\section{EMBRYRIDDLE \\ Aeronautical University}

SCHOLARLY COMMONS

\section{International Journal of Aviation,} Aeronautics, and Aerospace

$10-8-2017$

\title{
Blended Wing Body Propulsion System Design
}

Parth Kumar

Georgia Institute of Technology, pkumar75@gatech.edu

Adeel Khalid

Kennesaw State University, khalida1@erau.edu

Follow this and additional works at: https://commons.erau.edu/ijaaa

Part of the Aerodynamics and Fluid Mechanics Commons, Propulsion and Power Commons, and the Systems Engineering and Multidisciplinary Design Optimization Commons

\section{Scholarly Commons Citation}

Kumar, P., \& Khalid, A. (2017). Blended Wing Body Propulsion System Design. International Journal of Aviation, Aeronautics, and Aerospace, 4(4). https://doi.org/10.15394/ijaaa.2017.1187

This Article is brought to you for free and open access by the Journals at Scholarly Commons. It has been accepted for inclusion in International Journal of Aviation, Aeronautics, and Aerospace by an authorized administrator of Scholarly Commons. For more information, please contact commons@erau.edu. 
Since its inception, commercial aviation has rapidly progressed into a massive industry with millions of flights per year. The first fifty years led to the eventual rise of the cantilever, "tube and wing" design so commonly seen today, with the Boeing 707 being arguably the start of modern commercial aircraft design. In the years since the introduction of the 707 in 1958, aircraft have been made larger and more efficient, while retaining the same overall design. The progression of aircraft has slowly tapered off in the past few years; the gap between early 1920s commercial aviation and 1960s aviation is much greater than the gap between the 1960s and today. With rising fuel costs and the ever-growing demand for flight, it is necessary to restart the upward progression of aircraft. To do so, it is necessary to examine entirely new forms of aircraft - those that stray away from the tube and wing configuration. One of the most promising new concepts is the Blended Wing Body (BWB), in which the entire aircraft acts as a lifting surface, with no distinction between the fuselage and wings. Using a BWB suggests a lift to drag improvement of about 20\% over comparable tube and wing designs (Potsdam, Page, \& Liebeck, 1997; Qin et al., 2004), in addition to greater fuel and cost savings associated with further decreased weight. This paper will focus on optimizing the propulsion system of a potential BWB design. It will investigate the engine placement \& count, and the engine itself.

\section{Literature Review}

\section{BWB Aerodynamic Design Considerations}

While this project is centered on propulsion, the BWB is a highly integrated design that requires at least a preliminary analysis of other aspects of the aircraft. The BWB design combines the fuselage and the wing to create a more streamlined surface, as shown in Figure 1. It utilizes a centerbody airfoil on the fuselage section, resulting in an increased wetted aspect ratio, defined as $\frac{b^{2}}{s_{\text {wet }}}$, where $b$ is the wingspan and $S_{\text {wet }}$ is the wetted surface area. This provides a significant improvement in efficiency through decreased skin friction drag. The maximum lift to drag ratio is directly proportional to the square root of the wetted aspect ratio (Potsdam et al., 1997). According to Roman, Allen, and Liebeck (2000), the BWB has a $33 \%$ increase in wetted aspect ratio over a comparable tube and wing aircraft, in addition to other aerodynamic benefits regarding the span efficiency factor and wave drag. The following sections also examine several other aerodynamic considerations unique to the BWB. 


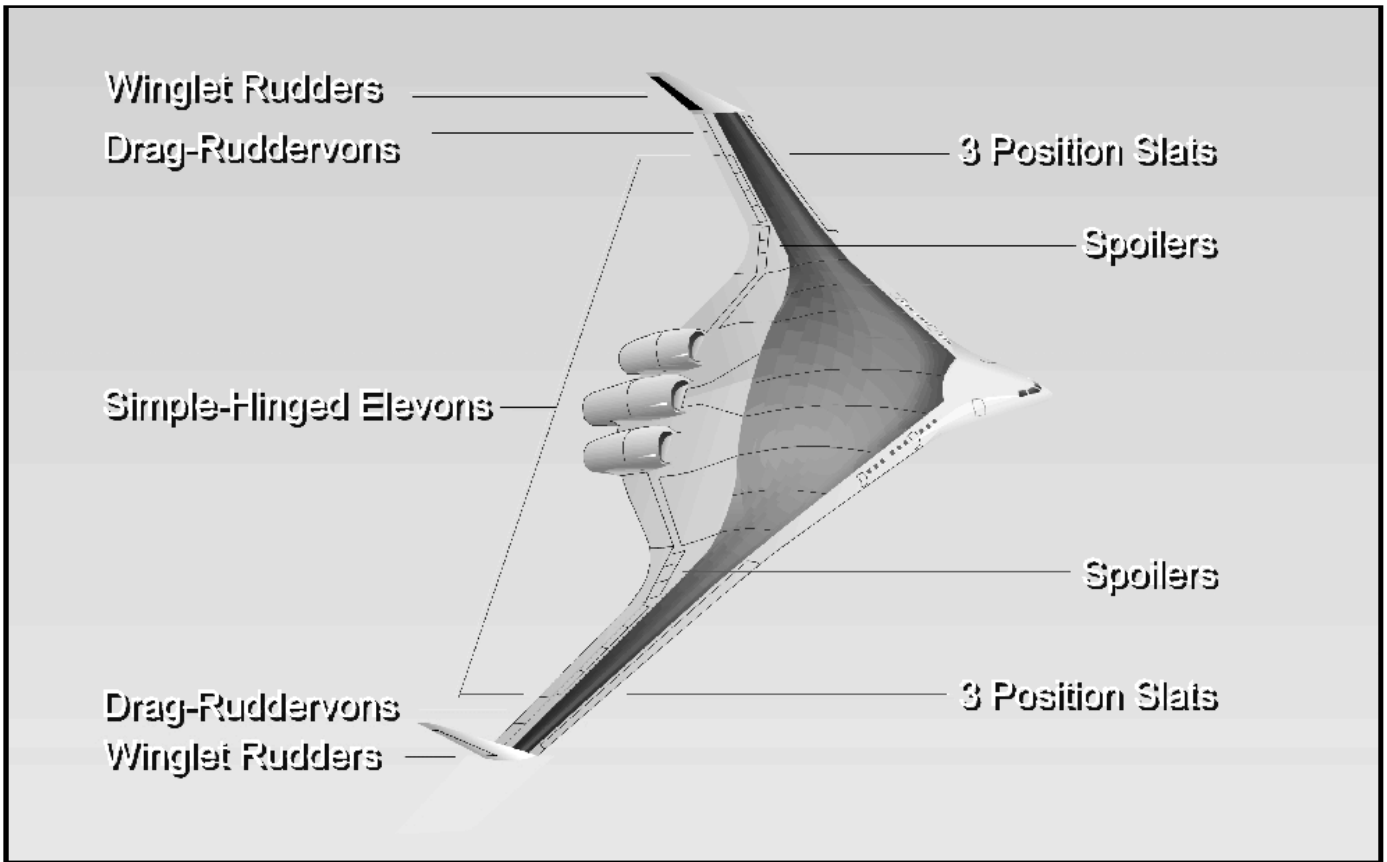

Figure 1: A BWB Concept (Liebeck, 2004)

\section{Induced and Wave Drag}

The BWB's design provides significant benefits in terms of induced and wave drag. The increase in the span efficiency factor allows for a significant increase in the lift to drag ratio that can be seen in Equation 1. The BWB also provides wave drag reduction due to the body naturally observing the area rule (Liebeck, 2003; Liebeck, 2004). This also allows the aircraft to have greater cruising speeds. According to Liebeck (2003), a BWB can travel efficiently at speeds of up to Mach 0.90, greater than the Mach 0.85 of traditional conventional aircraft.
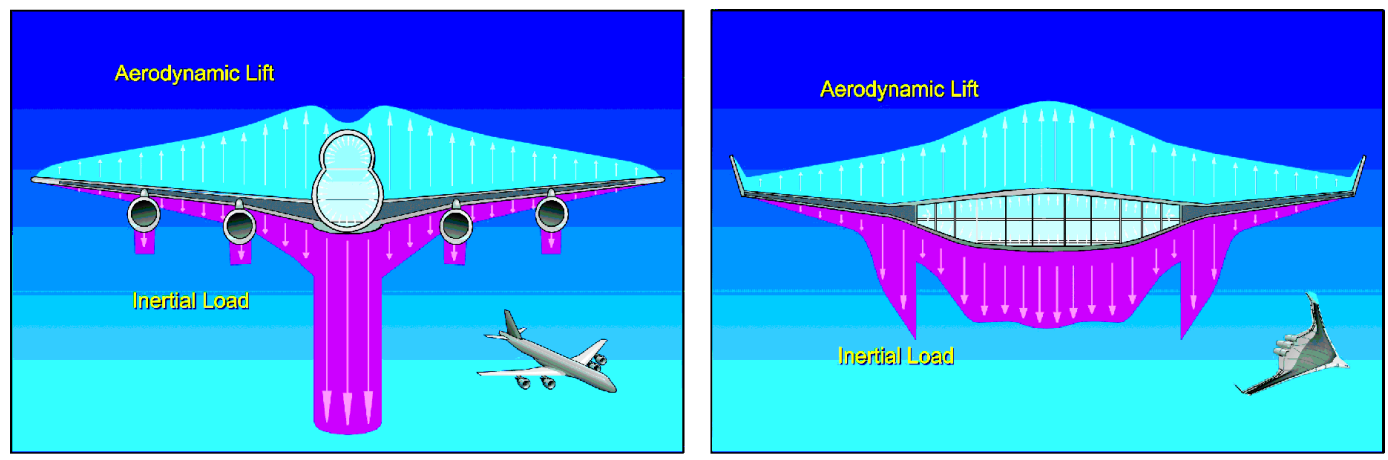

Figure 2: The BWB on the right shows a more elliptical lift distribution (Liebeck, 2004) 
However, minimization of the total drag, is more important than minimization solely of the induced or the wave drag. Qin, Vavelle, Le Moigne, Laban, Hackett, and Weinerfelt (2004) claim that an elliptic lift distribution does not minimize the total drag of an aircraft, in contrast to that of a tube and wing aircraft. Analysis of various lift distributions finds that an average lift distribution between an elliptic and a triangular provides the greatest lift to drag ratio when compared with only elliptic or only triangular distributions, with the elliptic distribution being ideal in terms of induced drag, but causing a large wave drag penalty, and the opposite for the triangular. Qin et al. (2004) also found a significant improvement in the lift to drag ratio over the baseline lift distribution by utilizing an averaged distribution.

\section{Airfoil Design for Wing and Winglet}

The design of the passenger cabin of a BWB poses difficulties in airfoil selection. The large payload of a prospective BWB design requires centerbody airfoils to have thickness to chord ratios near 17-18, far greater than those seen on supercritical airfoils on today's commercial aircraft (Liebeck, 2004; Potsdam et al., 1997). Djojodihardjo and Wei (2012) stated that airfoils with large leading-edge radii are desired for the center as well. Roman et al. (2000) further stated that traditional supercritical airfoils should be used on the outer sections of the wing, while the center should use a reflexed airfoil in order to provide it with pitch trim, compensating for the lack of the tail. The airfoil design of the "kink" region between the cabin and the outer wing is done by simply allowing the supercritical airfoil to blend with the centerbody.

The role of the winglet in the BWB is markedly different from that of a conventional aircraft. While winglets do provide the same reduction in induced drag seen in tube and wing aircraft, winglets can also act as vertical stabilizers in tailless BWB designs (Roman et al., 2000). Qin et al. (2004) used a NACA 0012 airfoil to act as the airfoil sections of the winglet, suggesting design techniques are similar to those used in tube and wing aircraft.

\section{Family Design of a BWB}

The development of a family of BWBs presents an important design consideration. Without significant commonality between different designs, the developmental and operating costs would both be significantly greater than that of a tube and wing, decreasing the cost benefit that increased fuel efficiency would provide. To increase size, most tube and wing aircraft increase the length of the fuselage and increase the wingspan; however, this would be unfeasible for a BWB, 
as that would significantly change the lift distribution and dynamics of the aircraft. Rather, Liebeck $(2003,2004)$ suggested using horizontal stretching to provide this family concept. This would increase both the span of the aircraft and the passenger capacity. A simple method of doing so is using separate "bays," which can be added on. Therefore, while only one mission profile will be investigated in this paper, a modular approach can allow for expansion to other roles for the BWB later on.

\section{Propulsion System Design}

The primary focus of this study is to optimize the propulsion system of the BWB. The shape of the aircraft will be determined using the significant body of available literature, rather than a detailed analysis. There are two different parts of propulsion system optimization for a BWB: the type of engine(s), and the placement of the engines.

There are several differences in the design of an efficient propulsion system for a tube and wing aircraft and a BWB. For example, engine location and count are among these differences. The most common location of the engines on a tube and wing aircraft is under each wing. For a BWB, many conceptual designs utilize a set of aft mounted engines on pylons, or integrated into the wing (for example: Liebeck, 2004; Nickol \& McCullers, 2009; Potsdam et al., 1997; Roman et al., 2000). The traditional under wing method greatly increases drag of the BWB by negatively altering the lift distribution. Dommelen \& Vos (2012) conducted a comparison between wing-mounted and aft-mounted designs. The study found that the aft mounted design had a significantly greater average and maximum lift to drag ratio-more than $10 \%$-mainly due to decreased drag of this design. The study finds that the aft mounted BWB has lower lift coefficients with flaps down (leading to longer takeoff/landing runways) and a center of gravity farther back on the fuselage; this leads to a greater static margin and low stability. With the apparent tradeoff, this study considers a detailed analysis of different engine placements.

Hanlon (2012) and Ko, Leifsson, Mason, Schetz, Grossman, and Haftka (2003) conducted a detailed analysis of a new idea in BWB propulsion called Boundary Layer Ingestion (BLI). BLI uses embedded propulsion to fill in the wake of the aircraft, increasing propulsive efficiency through the intake of air on the trailing edge of the aircraft. As a result, the engine reenergizes the part of the wake that normally travels at a lower velocity.

Another concept is distributed propulsion, which involves utilizing many smaller engines along the wing, rather than few powerful ones. Ko et al. (2003) suggests that a combination of distributed propulsion and boundary layer ingestion 
will yield greater efficiency due to several factors. First, it fills the entire wake as a jet wing concept. Second, the use of non-embedded distributed propulsion, in which many engines are mounted either over or under-wing on cowlings, would create a significant increase in wetted area and drag (Hanlon, 2012). The use of distributed propulsion also gives the aircraft increased redundancy in case of engine failure. This study proposes a vectored thrust system to replace control surfaces because a distributed propulsion system would involve using most of the trailing edge. While this paper will not consider designs with BLI, it should be noted that BLI has several implications for further optimization - especially regarding aft engine placement. This paper will analyze one distributed propulsion system.

\section{Aircraft Mission Profile \& Reference Aircraft}

According to Nickol (2012), the BWB would be effective as a medium to large long-range aircraft. The Boeing 777-200LR is the conventional control model, and its mission profile and characteristics are used as a guide in the design of this BWB. Table 1 shows a list of parameters of the Boeing 777-200LR. Figure 3 shows the mission profile for the Boeing 777-200LR

Table 1

Boeing 777-200LR Characteristics. Data from Boeing, 2015

\begin{tabular}{lc}
\hline Characteristic & Value \\
\hline Seating (3-class) & 301 seats (16 first, 58 business, 227 economy) \\
Engines & Two GE90-110/-115, 110,100/115,300 lbs. each \\
Cruise & Mach $0.84(35,000 \mathrm{ft})$. \\
Maximum Fuel & 181,280 L or 202,570 L (Fuel Tanks) \\
Maximum Takeoff Weight & $347,450 \mathrm{~kg}$ \\
(MTOW) & \\
Maximum Range & $212 \mathrm{ft} .7$ in $(64.8 \mathrm{~m})$ \\
Wing Span & $209 \mathrm{ft} .1$ in $(63.7 \mathrm{~m})$ \\
Length & $61 \mathrm{ft} .1$ in $(18.6 \mathrm{~m})$ \\
Tail Height & $19 \mathrm{ft} .3$ in $(5.86 \mathrm{~m})$ \\
Cabin Width & $20 \mathrm{ft} .4$ in $(6.19 \mathrm{~m})$ \\
Diameter & $145,150 \mathrm{~kg}$ \\
Operating Empty Weight & $209,000 \mathrm{~kg}$ \\
Max Zero Fuel Weight & $0.803 \mathrm{~kg} / \mathrm{L}$ \\
Fuel Density & nautical miles, $17,395 \mathrm{~km}$. \\
\hline
\end{tabular}




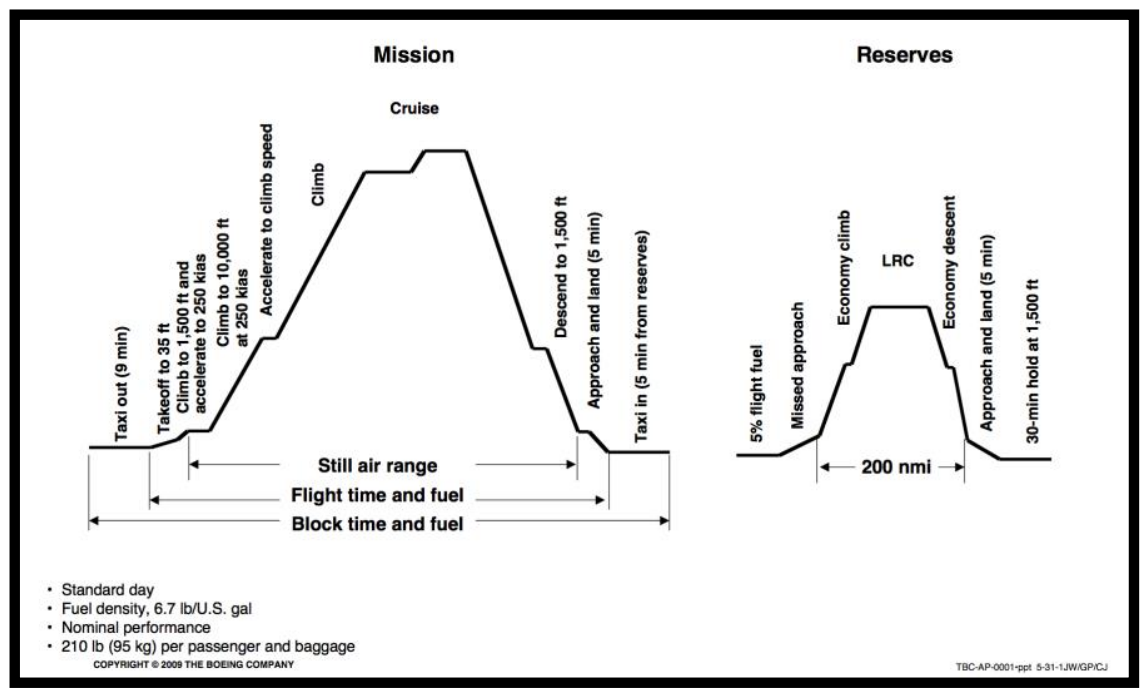

Figure 3: Mission Profile of a Boeing 777-200LR. From Boeing.

\section{Initial Design of the BWB}

The following parameters are to be held constant between the Boeing 777200LR and the BWB being designed:

Table 2

Constant Characteristics between BWB and 777-200LR. Data from Boeing, 2015

\begin{tabular}{lc}
\hline Characteristic & Value \\
\hline Seating (3-class) & 301 passengers (16 first, 58 business, \\
& 227 economy) \\
Cruise & Mach $0.84(35,000 \mathrm{ft})$. \\
Fuel Density & $0.803 \mathrm{~kg} / \mathrm{L}$ \\
Maximum Range & 9,395 nautical miles, $17,395 \mathrm{~km}$.
\end{tabular}

The aircraft's body design and weight calculations are done under the assumption that the parameters in Table 2 are held constant. The objective is to keep the wingspan under 80 meters so it can still fit inside the standard box size at international airports, and minimize the zero-fuel weight of the aircraft.

The following image shows the top view of the BWB, including the cabin, created in Autodesk Inventor with these parameters in mind. The shape was roughly determined through analysis of previous designs in literature (i.e. ranges for parameters such as wing sweep, aspect ratio, etc.) such as the BWBs shown in Bradley (2004), Ko et al. (2003), and Liebeck (2003). Detailed design of the shape was not conducted. This preliminary design is used only to provide approximate 
parameters such as length, span, wing area, etc. of a BWB that can carry the required number of passengers, allowing us to perform weight analysis.

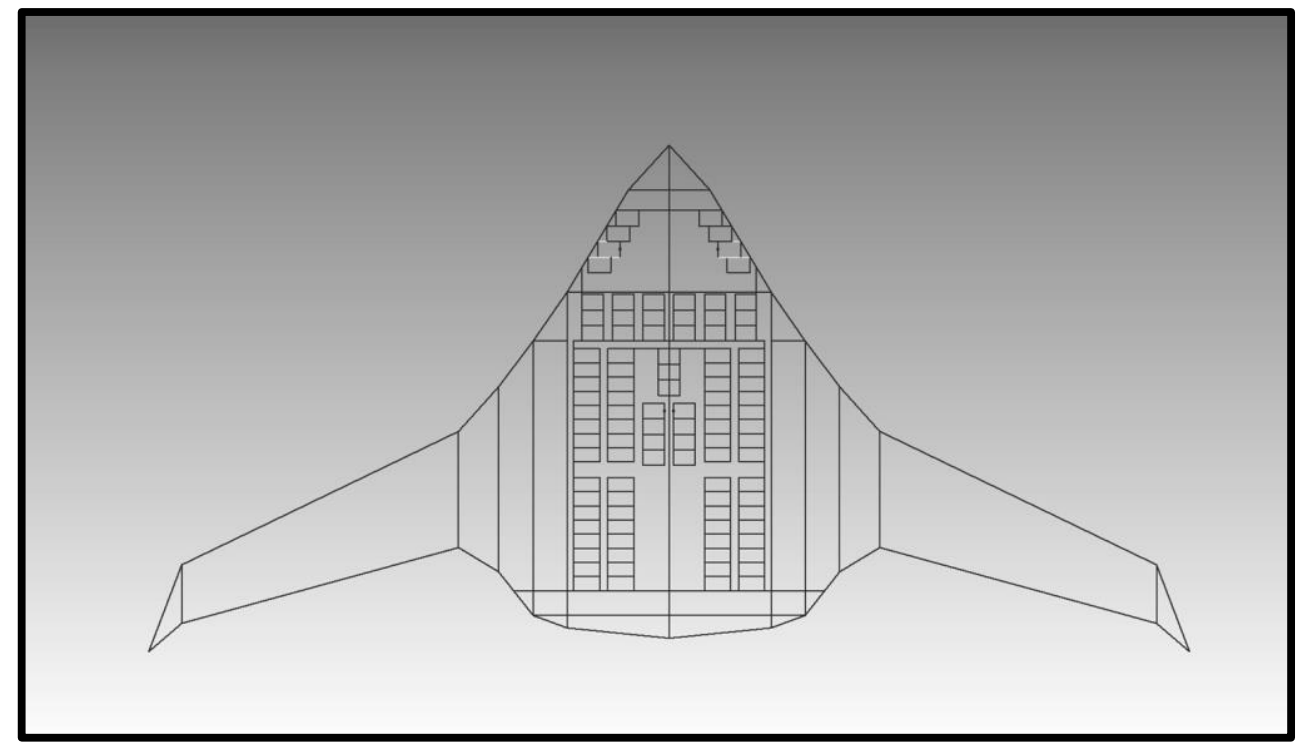

Figure 4. Top View of BWB wings and cabin design

\section{Aircraft Weight Estimation}

This section shows the computations of the approximate weight of the BWB design. We will assume three aft mounted engines in order to find the approximate weight. Once the exact engines are determined, weight calculations will be redone to get more accurate data. First, from the planform of the baseline BWB shown in Figure 4, we may find the following geometric parameters, where $S_{r e f}$ is the reference area, $S_{\text {cabin }}$ refers to the area of the cabin, etc., and $\lambda_{a f t}$ is the taper ratio of the aft surface.

Table 3

Geometric Parameters of BWB Design

\begin{tabular}{lc}
\hline Parameter & Value \\
\hline$S_{\text {ref }}$ & $765.324 \mathrm{~m}^{2}$ \\
$S_{\text {cabin }}$ & $299.138 \mathrm{~m}^{2}$ \\
$S_{\text {aft }}$ & $35.674 \mathrm{~m}^{2}$ \\
$S_{\text {wings }}$ & $401.92 \mathrm{~m}^{2}$ \\
$S_{\text {wingtips }}$ & $7.994 \mathrm{~m}^{2}$ \\
$S_{\text {misc }}$ & $20.598 \mathrm{~m}^{2}$ \\
$\lambda_{\text {aft }}$ & 0.54 \\
\hline
\end{tabular}


For the majority of components, the weight is found by using formulas explicitly stated by either Kroo (2001) or Bradley (2004). The exceptions are shown here.

\section{Wing Weight}

This is approximated using data from tube and wing aircraft, and the relation between wing area and wing weight. Ko et al.'s (2003) BWB 450 design had a $59,591 \mathrm{~kg}, 1245 \mathrm{~m}^{2}$ surface area wing, and the Boeing 747-200 had a $22858 \mathrm{~kg}, 511 \mathrm{~m}^{2}$ surface area wing. Since the fuselage is also effectively part of the wing in this case, the entire reference area is used to compute this value. Estimating with the line between the data points we have $W_{\text {wing }} \approx 35,553.7 \mathrm{~kg}$ or $78382.4 \mathrm{lbs}$. Finding precise values of the wing weight proved difficult, preventing the use of more data points to find a better curve fit.

\section{Propulsion System Weight}

According to Kroo (2001), the required amount of thrust for a BWB would be $0.25^{*} \mathrm{TOW}$ for a three-engine jet at takeoff, where TOW is the takeoff weight. We can approximate the thrust to weight (T/W) ratio of the engines as six for this study. From here, the propulsion system weight can be taken as $1.6 *$ Dry Weight. Thus, the propulsion system weight is about

$$
1.6 * \frac{0.25 * \text { TOW }}{6}=\frac{\text { TOW }}{15}
$$

\section{Payload Weight}

Assuming 11 flight attendants and five crew members (Kroo, 2001), we have a weight contribution for them of:

$11 * 210+5 * 240=3510 \mathrm{lbs}$.

For the 301 passengers, including luggage weight we have $225 \mathrm{lbs} * 301=$ $67,725 \mathrm{lbs}$, so $W_{\text {payload }}=71,235 \mathrm{lbs} .=32,312 \mathrm{~kg}$

\section{Fuel Weight}

To find a baseline figure for the fuel needed, we will assume that the thrust force would have to be equivalent to the drag force over the course of the aircraft's flight, from where we can find fuel consumption. We can write 


$$
D_{\text {total }}=\frac{1}{2} \rho v^{2} S_{r e f} C_{D}
$$

Where $D_{\text {total }}$ is the total drag of the aircraft, $C_{D}$ is the drag coefficient for the aircraft, $\rho$ is the air density, and $v$ is velocity. $S_{\text {ref }}$ is the the overall reference area. The $C_{D}$ used for a large BWB by Ko et al. (2003) is approximately 0.01 , which we will use to estimate drag coefficient at this very early stage. Using air density at 11,000 meters, and a velocity of Mach 0.89 - the 777-200LR's max speed - we find the total thrust force as

$$
\begin{gathered}
F_{\text {thrust }}=D_{\text {total }}=\left(\frac{1}{2}\right) * 0.36 * 295^{2} * 765.324 * .01=119884 \mathrm{~N} \\
=12224 \mathrm{~kg} \mathrm{f}=26951 \mathrm{lb} . \mathrm{f}
\end{gathered}
$$

The specific fuel consumption of engines during cruise for aircraft like the 747-400 and the 777-200LR stands at around 0.5-0.6 (Van Es \& Gerard, 2002). We shall use the average at 0.55 . At Mach $0.84,11,000$ meters, the aircraft would take about 16.36 hours to travel $9,380 \mathrm{nmi}$. We can find the fuel consumption with $26951 * 0.55 * 16.36=242,505 \mathrm{lbs}$ of fuel used as an approximate figure for initial weight estimations. By comparison, a Boeing 777-200LR has a fuel consumption of approximately 301,381 lbs. for the same flight, based on data provided by Boeing.

\section{Overall Weights: Summary}

The following table lists all of the component weights, and the equations used to find them. Additionally, it provides a summary of the previous computations.

Table 4

Component Weights

\begin{tabular}{lccc}
\hline Components & Equations, units in lbs., $\mathrm{ft}^{2}$ & Ref. & Weight $(\mathrm{lbs})$. \\
\hline Wing Weight & Approximated from $\mathrm{S}_{\text {ref }}$ & - & 78382.4 \\
Cabin Weight & $5.699 * 0.316(\text { TOW })^{0.167}\left(S_{\text {cabin }}\right)^{1.06}$ & Bradley & $\begin{array}{l}9515.43 \\
\end{array}$ \\
& & & $*$ TOW $W^{0.167}$ \\
& & & \\
Aft Surface & $\left(1+0.05 * N_{\text {eng }}\right) * 0.53 * S_{\text {aft }} *$ TO $W^{0.2}$ & Bradley & 243.405 \\
& $*\left(\lambda_{\text {aft }}+0.5\right)$ & & $*$ TOW
\end{tabular}




\begin{tabular}{|c|c|c|c|}
\hline $\begin{array}{l}\text { Propulsion } \\
\text { System }\end{array}$ & $\frac{\text { TOW }}{15}$ & - & $\frac{\text { TOW }}{15}$ \\
\hline Payload Weight & $\begin{array}{c}\text { From number of passengers, flight } \\
\text { attendants, and luggage }\end{array}$ & - & 71,235 \\
\hline Fuel Weight & Computation described above & - & 242505 \\
\hline Landing Gear & $0.04 *$ TOW & Kroo & $0.04 *$ TOW \\
\hline $\begin{array}{l}\text { Surface Controls: } \\
\text { Wing }\end{array}$ & $I_{s c} *\left(S_{s c}\right), I_{s c}=3.5^{*}$ & Kroo & $5035^{* *}$ \\
\hline $\begin{array}{l}\text { Instruments \& } \\
\text { Nav. Equip. }\end{array}$ & Constant & Kroo & 1200 \\
\hline $\begin{array}{l}\text { Hydraulics \& } \\
\text { Pneumatics }\end{array}$ & $0.65 * S_{\text {ref }}$ & Kroo & 5354 \\
\hline Electronics & Constant & Kroo & 1500 \\
\hline Furnishings & $101.6 N$, where $\mathrm{N}$ is the number of seats & Kroo & 30,582 \\
\hline $\begin{array}{l}\text { Air Conditioning/ } \\
\text { /Anti Ice }\end{array}$ & $15 N$ & Kroo & 4515 \\
\hline $\begin{array}{l}\text { Operating Items } 1 . \\
\text { Crew }\end{array}$ & $40 N$ & Kroo & 12040 \\
\hline APU & $7 N$ & Kroo & 2107 lbs. \\
\hline Electrical & $13 N$ & Kroo & 3913 lbs. \\
\hline
\end{tabular}

*Modified for purposes of BWB

**Area of the surface controls is approximated as $33 \%$ of the wing area $* * * \mathrm{~N}=$ number of passenger seats

Adding all the component weights, we have

$$
\begin{gathered}
W_{\text {total }}=W_{\text {structures }}+W_{\text {misc }}+W_{\text {payload }}+W_{\text {fuel }} \\
W_{\text {total }}=W_{\text {wing }}+W_{\text {aft }}+W_{\text {prop }}+W_{\text {cabin }}+W_{\text {misc }}+W_{\text {payload }}+W_{\text {fuel }} \\
W_{\text {total }}=78382 \mathrm{lbs}+243.405 * \text { TOW } W^{0.2}+\frac{\text { TOW }}{15}+9515.43 * \text { TO } W^{0.167} \\
+66246+0.04 * \text { TOW }+71,235+242505
\end{gathered}
$$

However, note that $W_{\text {total }}=$ TOW in this case, as we have full fuel load. So, solving the equation, we have that 


$$
W_{\text {total }}=T O W=615,700 \mathrm{lbs}
$$

From here we find empty weight $W_{\text {empty }}=W_{\text {total }}-W_{\text {payload }}-W_{\text {fuel }}=$ $301,960 \mathrm{lbs}$. By comparison, the empty weight of the Boeing 777-200LR is 320,000 .

\section{Aircraft Design: Airfoil Selection}

We will consider the lift distribution and the static margin in our limited analysis of the aerodynamic design of this BWB.

\section{Lift Distribution}

The study requires that the BWB's lift at zero degrees angle of attack can support the empty weight of the aircraft, payload, and five percent fuel. This requirement prevents the aircraft from having to pitch downward near the end of the cruise portion of the flight, after most fuel has been consumed and mainly reserves remain. Flying with more fuel is accomplished by increasing the angle of attack. Using our weight calculations and adding approximately a 15,000 lbs. margin gives us the requirement that

$$
\int_{-31.352}^{31.352} L(y) d y=400,000 \text { lbs } f \approx 1780,000 \text { Newtons }
$$

where $y$ is distance along the span from the centerline of the BWB, and $L(y)$ is the lift per unit span as a function of $y$.

We want the lift distribution $L(y)$ to be elliptical. To find the exact distribution, note that $\pi a * 31.352=2 * 1,780,000$, where $a$ is the lift per meter span at the center of the wing. As the initial calculations integrated only the upper half of the ellipse, we have a factor of two on the right side to correct for this. Then expressing in standard form, we find the equation is then

$$
\frac{L^{2}}{36144^{2}}+\frac{y^{2}}{31.354^{2}}=1
$$

Solving for $L$, we have

$$
L(y)=\frac{1}{2} \rho v^{2} C(y) * C_{L}(y)=9.22 \sqrt{1.536 * 10^{7}-15625 * y^{2}}
$$


which is elliptical, and satisfies the weight requirement from above. $C(y)$ is the chord as a function of $y$ and $C_{L}(y)$ is the lift coefficient as a function of $y$.

The chord function is determined by analyzing the BWB design shown previously in Figure 4, and can be found in the Appendix. Using that chord function, the equation for $C_{L}(y)$ can easily be determined, as we can solve for the lift coefficient with respect to span that is required from the above equation for lift:

$$
C_{L}(y)=C(y)^{-1} * 0.000589 \sqrt{1.536 * 10^{7}-15625 * y^{2}}
$$

The above equation is evaluated at six points on the span; then, at these points, airfoils with the ideal lift coefficient values are found. These airfoils are then lofted/combined together in Autodesk Inventor to create the model of the wing. This is approximating the ideal $C_{L}(y)$ function with line segments.

To demonstrate this more clearly, Figure 5 shows the ideal graph of the $C_{L}(y)$ that produces a perfectly elliptical lift distribution with a graph of $C_{L}(y)$, which is the result of the process described in the paragraph above. Table 5 shows the airfoils, the equation for the linear portion of the lift curve, and respective incidence angles used, as well as the span location of each airfoil.

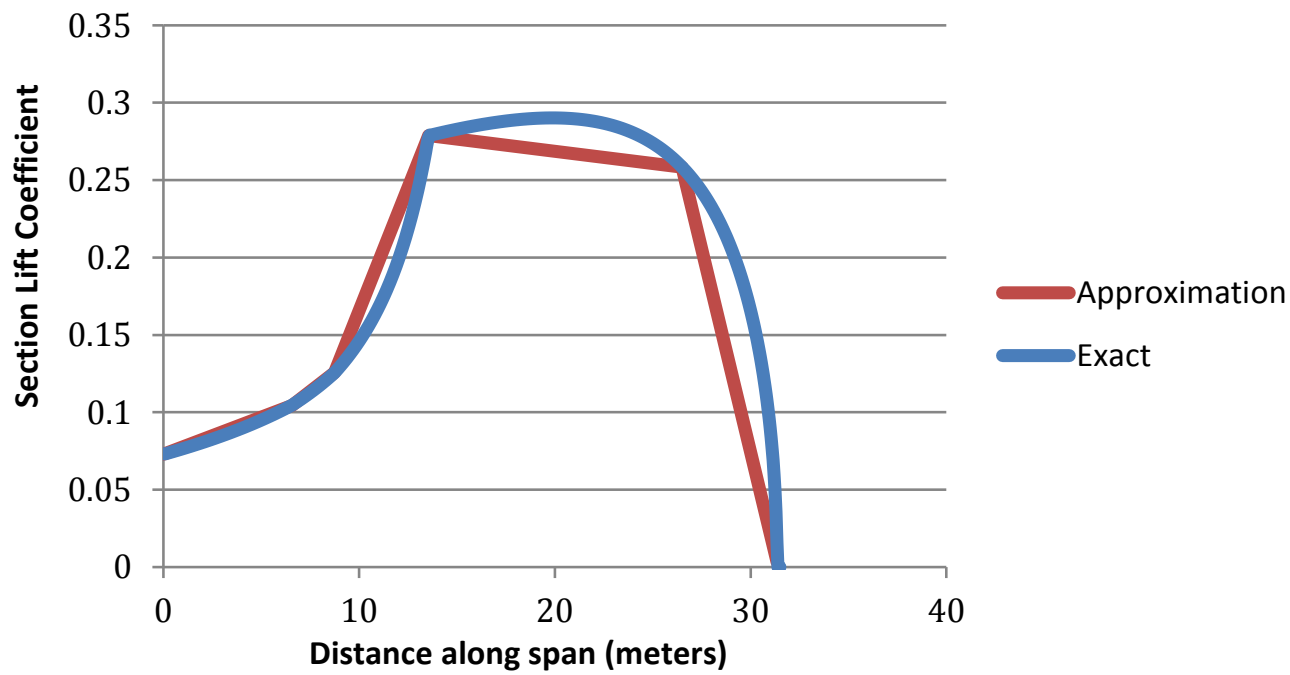

Figure 5: Ideal graph of $\boldsymbol{C}_{\boldsymbol{L}}(\boldsymbol{y}) \&$ approximation developed by lofting airfoils 
Table 5

Airfoils, Angle of Incidence, and Lift Coefficient $\left(\boldsymbol{C}_{\boldsymbol{L}}\right)$ vs. Angle of Attack $(\boldsymbol{\alpha})$

\begin{tabular}{|c|c|c|c|}
\hline Airfoil & Equation $\left(C_{L} v s \alpha\right)$ & Incidence Angle & Point on Span \\
\hline Designed* & $C_{L}=0.1213 \alpha+0.0803$ & 0 degrees $* *$ & $\begin{array}{c}0 \text { meters } \\
(\text { Centerbody) }\end{array}$ \\
\hline $\begin{array}{l}\text { NASA SC(2)- } \\
0012\end{array}$ & $C_{L}=0.112 \alpha$ & 0.933 & 6.559 meters \\
\hline $\begin{array}{l}\text { NASA SC(2)- } \\
0010\end{array}$ & $C_{L}=0.1099 \alpha$ & 1.143 & 8.745 \\
\hline Lockheed GA & $C_{L}=0.11 \alpha+0.1176$ & 1.465 & 13.548 \\
\hline $\begin{array}{l}\text { NASA SC(2)- } \\
606\end{array}$ & $C_{L}=0.1194 \alpha+0.3371$ & -0.659 & 26.500 \\
\hline $\begin{array}{l}\text { NASA SC(2)- } \\
406\end{array}$ & $C_{L}=0.1125 \alpha+0.1559$ & -1.385 & $\begin{array}{c}31.352 \text { (end of } \\
\text { wing) }\end{array}$ \\
\hline
\end{tabular}

*Centerbody airfoil designed in XFOIL due to lack of airfoils with high thickness-chord and supercritical characteristics.

** Centerbody is kept at a slightly higher lift coefficient due to interference effects from engines

\section{Static Margin}

The static margin of the wing with the above airfoil combinations is computed with mathematical analysis. A positive static margin is required for stability, which is critical in such large commercial aircraft. The location of the neutral point with respect to the front of the aircraft is approximately 16.08 meters in. The computation is too long to be shown here, but can be found in the Appendix.

We can assume the location of the center of gravity is at approximately $50 \%$ of the chord length for the aft propulsion configuration, which is the case with the center of gravity farthest back (corresponding to the lowest static margin/worst case scenario). The location would then be at 15.85 .

We require a positive static margin

$$
\text { static margin }=\frac{X_{A . C .}-X_{C . G}}{c}>0
$$

Where $X_{\text {A.C. }}$ is the distance from the leading edge of the aircraft to the neutral point/aerodynamic center. $X_{C . G}$ is the distance from the leading edge to the center of gravity, and $c$ is the chord of the aircraft. Since the entire aircraft is acting as a wing, the front of the plane is the leading edge, thus the static margin is approximately 


$$
\frac{16.08-15.85}{31.7}=0.74 \%
$$

These airfoils are satisfactory, as the static margin is positive. While it is quite low, especially for a large commercial aircraft, it could be further improved by slight changes in geometry or reorganization of payload, if needed.

\section{Aircraft Design: Baseline Images}

When combined, the airfoil determinations from above and our earlier sketch in Figure 6 provide the following baseline BWB:

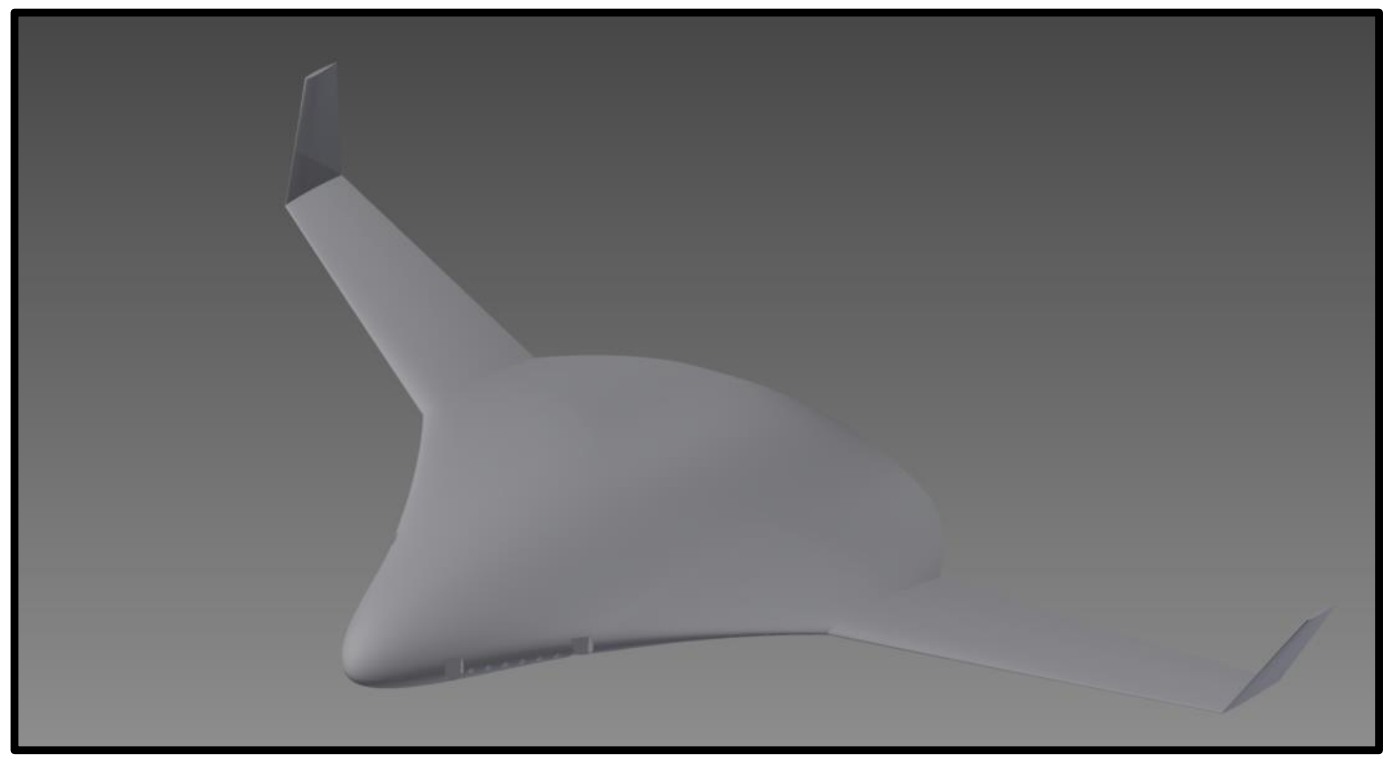

Figure 6. The Baseline BWB, on which different engine variations will be analyzed and compared

\section{Propulsion Optimization Stage One: Engine Selection}

The optimal engine would be one that provides the following:

1. Proper Takeoff Distance (less than or equal to 3000 meters)

2. Adequate Climb Performance

3. Specific Fuel Consumption (SFC)

4. Minimal excess thrust

The first two requirements are constraints that must be satisfied; after which, the engine with a proper balance of excess thrust and SFC will be used. Note that excess 
thrust should be minimized in order, as larger engines have greater weight and parasitic drag. First, we will show the derivation of the various formulas that are to be utilized in computing the above performance parameters.

\section{Thrust Lapse Rate Formula Derivation}

The maximum thrust an engine can produce is a function of height $\&$ Mach number. Let $T_{M, h}$ be the thrust at Mach number $M$ and altitude h. Also let $T_{0}$ be sea level static thrust. According to Trani (n.d.) (n.d.), we have

$$
T_{M, h}=\left(T_{0}-\lambda M\right) *\left(\frac{\rho_{h}}{\rho_{0}}\right)^{k}
$$

where $\mathrm{k}$ and $\lambda$ are constants, $\rho_{h}$ is the air density at height $\mathrm{h}$ and $\rho_{0}$ is sea level air density. Trani (n.d.) also suggests that we can let the constant $k \approx 0.9$. Furthermore, much of the data available on engines provides two data points: sea level static thrust and cruise thrust. These data points are sufficient to solve for $\lambda$. Let subscript $c$ represent cruise conditions, then

$$
\begin{gathered}
T_{c}=T_{M_{c}, h_{c}}=\left(T_{0}-\lambda M_{c}\right) *\left(\frac{\rho_{c}}{\rho_{0}}\right)^{0.9} \\
\lambda=\frac{T_{0}-T_{c} *\left(\frac{\rho_{0}}{\rho_{c}}\right)^{0.9}}{M_{c}}
\end{gathered}
$$

Thus, we have our overall total thrust model as follows:

$$
\begin{aligned}
T_{M, h}=\left(T_{0}-M * \frac{T_{0}-T_{c} *\left(\frac{\rho_{0}}{\rho_{c}}\right)^{0.9}}{M_{c}}\right) *\left(\frac{\rho_{h}}{\rho_{0}}\right)^{0.9} \\
=\left(T_{0}+\frac{M}{M_{c}} *\left(T_{c} *\left(\frac{\rho_{0}}{\rho_{c}}\right)^{0.9}-T_{0}\right)\right) *\left(\frac{\rho_{h}}{\rho_{0}}\right)^{0.9}
\end{aligned}
$$

Where $T_{0}, T_{c}, M_{c}, \rho_{c}, \rho_{0}$ are all constant. $T_{0}, T_{c}$ are given for each engine, and depending on the aircraft the engine was designed for, the rest can be found.

\section{Takeoff Speed}

First, we must determine the takeoff velocity, $v_{\text {takeoff }}$. We can use 


$$
v_{\text {takeoff }}=1.2 * v_{\text {stall }}
$$

And by the definition of stall speed, at low altitude near sea level

$$
W=\frac{1}{2} \rho_{0} v_{\text {stall }}^{2} S_{\text {ref }} * C_{L_{\text {flapsdown }}}
$$

where $W$ is weight, and $\rho_{0}$ is air density at sea level. Literature suggests max lift coefficient values between 2 and 2.5 for a typical flaps-down takeoff scenario. We shall use the lower bound of two, since it is preferable for the calculated takeoff distance to be slightly larger than the actual distance, due to runway length constraints. We take the weight to be slightly higher than the approximate max fuel weight of 616,000 lbs. We use 640,000 lbs. as standard takeoff weight for max range. Using SI units for everything, we have

$$
v_{\text {stall }}=\sqrt{\frac{2 W}{\rho_{0} S_{\text {ref }} C_{\text {Lflapsdown }}}}=\sqrt{\frac{2 * 2.847 * 10^{6} \mathrm{~N}}{1.225 \frac{\mathrm{kg}}{\mathrm{m}^{3}} * 765 \mathrm{~m}^{2} * 2}}=55.118 \mathrm{~m} / \mathrm{s}
$$

Thus, finally,

$$
v_{\text {takeoff }}=1.2 * \sqrt{\frac{2 W}{\rho_{0} S_{\text {ref }} C_{\text {Lflapsdown }}}}=1.2 * v_{\text {stall }}=66.14 \mathrm{~m} / \mathrm{s}
$$

Note that these calculations are performed for conditions at sea level.

\section{Takeoff Distance}

From Oates (1989), we have the following formula for the takeoff distance $S$, where $v_{\text {takeoff }}=v_{f}, g$ is gravity, $T$ is thrust, $L$ is total lift force, $D$ is total drag force, and $\mu$ is the coefficient of friction of the runway.

$$
S=\int_{0}^{v_{f}} \frac{W}{g} * \frac{v}{(T-D-\mu(W-L))} d v
$$

Oates (1989) suggested a friction coefficient of about 0.02. Additionally, writing lift and drag in terms of velocity and coefficients gives us the following equation: 


$$
S=\int_{0}^{v_{f}} \frac{W}{g} * \frac{v}{\left(T-\frac{1}{2} \rho_{0} v^{2} S_{r e f} C_{D}-0.02\left(W-\frac{1}{2} \rho_{0} v^{2} S_{\text {ref }} C_{L_{\text {flapsdown }}}\right)\right)} d v
$$

Note that we are ignoring wind speed. Now, while most constants are known in this equation, it remains to find the lift and drag coefficients. For lift, we will use the same flaps down $C_{L}=2$ from before. For drag, we approximate $C_{D}$ as

$$
C_{d 0}+\frac{C_{L}^{2}}{\pi A R e}
$$

where $C_{d 0}$ is the zero lift drag coefficient, $A R$ is the aspect ratio, and $e$ is the wing efficiency factor. Approximating $C_{d 0}$ from the airfoil sections, we find a value near 0.006. Note that this approximation excludes compressibility drag at high Mach numbers, so the drag will be different for other flight conditions. We will use $e=$ 0.95 for takeoff.

$$
C_{D}=0.006+\frac{2^{2}}{\pi * 67^{2} / 765 * 0.95}=0.006+0.228=0.234
$$

This is a very high drag coefficient for cruise performance, but for takeoff, it is not abnormal.

Next, our thrust model for takeoff can be simplified. We have that:

$$
T_{M, h}=\left(T_{0}+\frac{M}{M_{C}} *\left(T_{c} *\left(\frac{\rho_{0}}{\rho_{c}}\right)^{0.9}-T_{0}\right)\right) *\left(\frac{\rho_{h}}{\rho_{0}}\right)^{0.9}
$$

Note that $h=0$, so $M=\frac{v}{332}$ and $\rho_{h}=\rho_{0}$, giving us the following expression:

$$
T_{v}=T_{0}+\frac{v}{332 * M_{c}} *\left(T_{c} *\left(\frac{\rho_{0}}{\rho_{c}}\right)^{0.9}-T_{0}\right)
$$

Substituting the above, as well as $W$ and $g$, to get our overall equation,

$$
S=\int_{0}^{66.14} \frac{290,300 * v}{T_{0}+\frac{v}{332 * M_{c}} *\left(T_{c} *\left(\frac{\rho_{0}}{\rho_{c}}\right)^{0.9}-T_{0}\right)-90.9011 v^{2}-56880} d v
$$


Everything is in SI units. Thus, we can compute the takeoff distance in terms of various engine parameters. We know that the standard takeoff distance of the 777200LR as about 2,500 meters (Boeing, 2015). Our goal is to produce a BWB takeoff distance of similar length, and no more than 3,000 meters.

\section{Climb Rate}

The other important calculation that must be made is the climb rate. We can express the rate of climb as

$$
\frac{d h}{d t}=\frac{(T-D) * v}{m g}-\frac{v}{g} \frac{d v}{d t}
$$

Where $\frac{d h}{d t}$ is the climb rate, $m$ is mass and the other constants are as defined earlier. For simplicity, we ignore the right-hand term, as shown by Trani (n.d.):

$$
\frac{d h}{d t}=\frac{(T-D) v}{m g}
$$

Substituting the thrust lapse rate equation, we have

$$
\frac{d h}{d t}=\frac{\left(\left(T_{0}+\frac{M}{M_{c}} *\left(T_{c} *\left(\frac{\rho_{0}}{\rho_{c}}\right)^{0.9}-T_{0}\right)\right) *\left(\frac{\rho_{h}}{\rho_{0}}\right)^{0.9}-D\right) * v}{m g}
$$

Thus, for any given thrust, altitude, and speed we can compute the climb rate. The standard climb velocity of the 777-200LR is 250 knots below 10,000 feet $(128.6 \mathrm{~m} / \mathrm{s})$ and $310 \mathrm{knots}$ above $(160 \mathrm{~m} / \mathrm{s})$ (Boeing, 1999). The value of drag will be computed for the heights of $1,000,3,000,4,000$, and 6,000 meters. The derivation of the 1,000-meter case is shown below; the remainder of the cases are identical, except numerical differences due to air density and climb velocity.

1,000 meters. Substituting values for velocity, weight, and air density at 1,000 meters, we have

$$
\frac{d h}{d t}=\frac{\left(\left(T_{0}+\frac{0.382}{M_{c}} *\left(T_{c} *\left(\frac{1.225}{\rho_{c}}\right)^{0.9}-T_{0}\right)\right) * 0.907-D\right) * 128.6}{2.847 * 10^{6}}
$$


To find the drag, we express in terms of the coefficients once again. In steady climb, the entire climb rate occurs due to excess thrust, rather than lift. Thus,

$$
L=m g=\frac{1}{2} \rho v^{2} S_{r e f} * C_{L}, \text { so } C_{L}=\frac{2 m g}{\rho v^{2} S_{r e f}}=0.41
$$

Then, assuming the same zero lift drag as at sea level, we have

$$
\begin{gathered}
C_{D}=C_{d 0}+\frac{C_{L}^{2}}{\pi * A R * e}=0.0156 \\
D=\frac{1}{2} \rho v^{2} S_{r e f} * C_{D}=\frac{1}{2} * 1.1 * 128.6^{2} * 765 *\left(C_{d 0}+\frac{C_{L}^{2}}{\pi * A R * e}\right) \\
D=\frac{1}{2} \rho v^{2} S_{r e f} C_{D}=108,550 \mathrm{~N}
\end{gathered}
$$

Thus, our final equation is

$$
\frac{d h}{d t}=\frac{\left(\left(T_{0}+\frac{0.382}{M_{c}} *\left(T_{c} *\left(\frac{1.225}{\rho_{c}}\right)^{0.9}-T_{0}\right)\right) * 0.907-108550\right) * 128.6}{2.847 * 10^{6}}
$$

3000 meters. Using the same process, we derive the following equation:

$$
\frac{d h}{d t}=\frac{\left(\left(T_{0}+\frac{0.391}{M_{c}} *\left(T_{c} *\left(\frac{1.225}{\rho_{c}}\right)^{0.9}-T_{0}\right)\right) * 0.77-113402\right) * 128.6}{2.847 * 10^{6}}
$$

4,000 meters. This time using $v=160 \mathrm{~m} / \mathrm{s}$,

$$
\frac{d h}{d t}=\frac{\left(\left(T_{0}+\frac{0.493}{M_{c}} *\left(T_{c} *\left(\frac{1.225}{\rho_{c}}\right)^{0.9}-T_{0}\right)\right) * 0.70-104382\right) * 160}{2.847 * 10^{6}}
$$


6,000 meters. Again using $v=160 \mathrm{~m} / \mathrm{s}$ at 6,000 meters, the climb rate is

$$
\frac{d h}{d t}=\frac{\left(\left(T_{0}+\frac{0.51}{M_{c}} *\left(T_{c} *\left(\frac{1.225}{\rho_{c}}\right)^{0.9}-T_{0}\right)\right) * 0.57-109866\right) * 160}{2.847 * 10^{6}}
$$

\section{Reduced/Derated Thrust}

In all of the above equations, we may add a de-rate factor $b_{\text {derate, }}$, to represent an engine not acting on maximum power. For example, the modified takeoff equation is displayed below:

$S=\int_{0}^{66.14} \frac{290,300 * v}{\left(T_{0}+\frac{v}{332 * M_{c}} *\left(T_{c} *\left(\frac{\rho_{0}}{\rho_{c}}\right)^{0.9}-T_{0}\right)\right) * b_{\text {derate }}-90.9011 v^{2}-56880} d v$

\section{Engine Data \& Selection}

The above equations were programmed into Wolfram Mathematica, and iterated upon to provide data for $\sim 150$ engines. The de-rate factors used were 1 (indicating 0\% reduction from maximum thrust), 0.9 (indicating 10\% reduction from maximum thrust), 0.8 (indicating $20 \%$ reduction from maximum thrust), and 0.7 (indicating 30\% reduction from maximum thrust). Each engine was tested for engine counts of 2,3,4, and 8. Data on cruise and sea level thrust was used from Meier (2005). Figures 7 and 8 display data from the two-engine case.

Note that in the engine thrust vs. takeoff distance, many engines are not able to even allow for the aircraft to lift off, and thus have no data point. Due to the large amount of data produced, we have included the most relevant data in this paper. As previously mentioned, the maximum allowed takeoff distance is 3,000 meters, and the following values in Table 6 are reference points for climb rates.

Table 6

Minimum Climb Rates

\begin{tabular}{lcccc}
\hline Altitude & $\underline{1000 \mathrm{~m}}$ & $\frac{3000 \mathrm{~m}}{11}$ & $\frac{4000 \mathrm{~m}}{10}$ & $\frac{6000 \mathrm{~m}}{7}$ \\
Climb Rate $(\mathrm{m} / \mathrm{s})$ & 14 & 11 & 10 & 7 \\
\hline
\end{tabular}




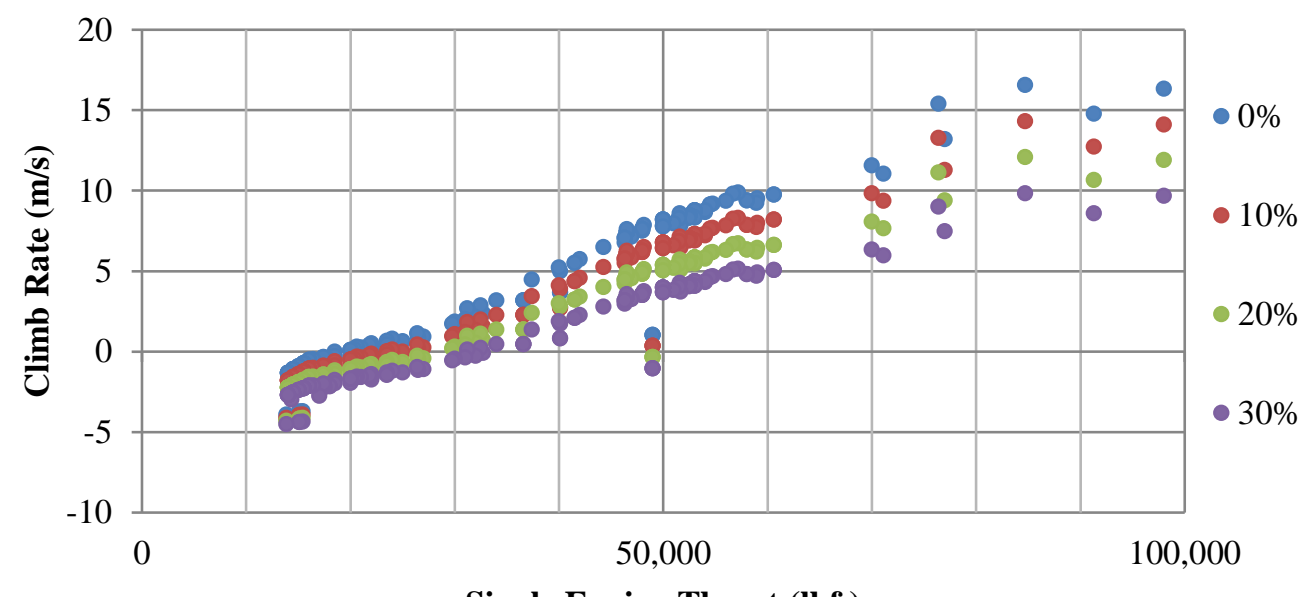

Single Engine Thrust (lbf.)

Figure 7. Climb rate at 3000 meters for the two-engine case. The different colors/percentages correspond to different de-rate percentages.

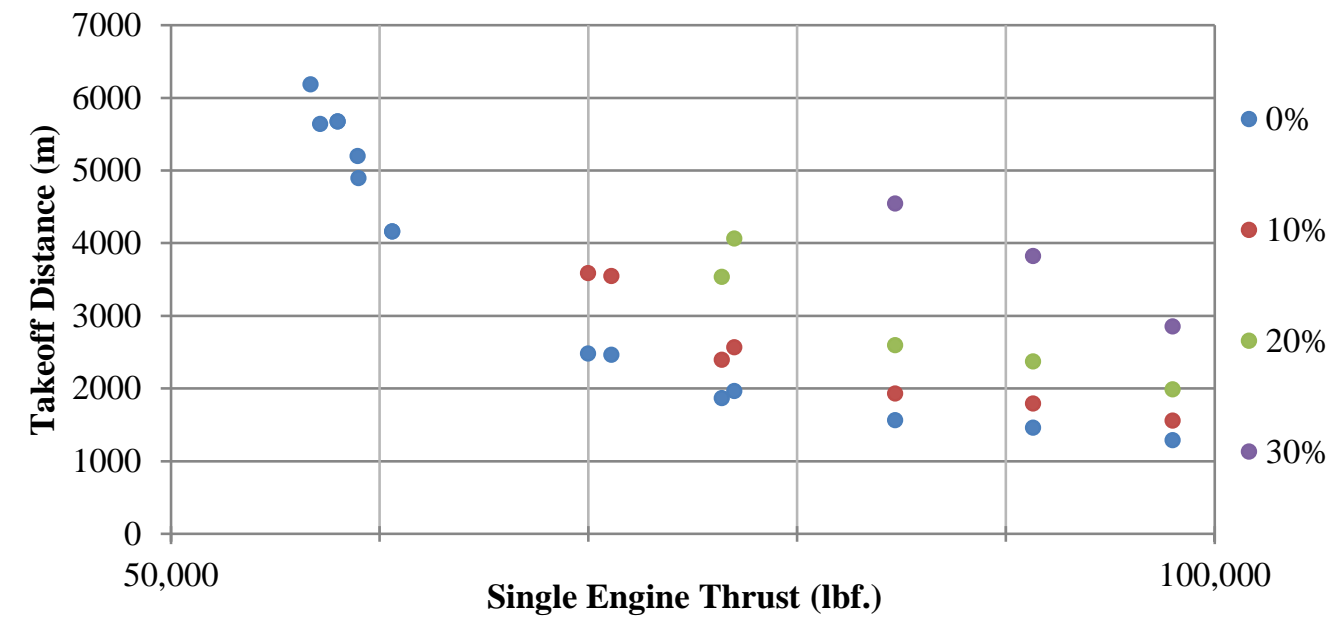

Figure 8. Takeoff distance for the two-engine case. The different colors/percentages correspond to different de-rate percentages.

The following data represents the final engines selected for each case. The engines selected generally had a good combination of low excess thrust and SFC, along with satisfying climb and takeoff rates. 
Table 7

Engine Selection \& BWB Design Performance. Engine Data from Meier (2005).

\begin{tabular}{|c|c|c|c|c|c|}
\hline Configuration & $\begin{array}{l}2 \\
\text { Engines }\end{array}$ & $\begin{array}{l}3 \\
\text { Engines }\end{array}$ & $\begin{array}{l}3 \quad(10 \% \\
\text { Derate })\end{array}$ & $\begin{array}{l}4 \\
\text { Engines }\end{array}$ & $\begin{array}{l}8 \\
\text { Engines }\end{array}$ \\
\hline Engine Name & $\begin{array}{c}\text { RR } \\
\text { Trent } \\
772-60\end{array}$ & \multicolumn{2}{|c|}{ GE CF6-80C2A2 } & $\begin{array}{l}\text { CFM56- } \\
5 \mathrm{C} 4\end{array}$ & $\begin{array}{l}\text { Solovyev } \\
\text { PS-7 }\end{array}$ \\
\hline Engine Thrust (lbs. f) & 71,100 & 52,460 & 47,214 & 34,000 & 17,000 \\
\hline Takeoff Run (m) & 2458 & 1781 & 2262 & 2554 & 2592 \\
\hline $\begin{array}{l}\text { Climb Rate } 1000 \text { meters } \\
(\mathrm{m} / \mathrm{s})\end{array}$ & 14.57 & 18.72 & 16.36 & 15.28 & 15.01 \\
\hline 3000 meters $(\mathrm{m} / \mathrm{s})$ & 11.28 & 14.83 & 12.84 & 11.92 & 11.69 \\
\hline 4000 meters $(\mathrm{m} / \mathrm{s})$ & 11.01 & 15.41 & 13.28 & 12.23 & 11.91 \\
\hline 6000 meters $(\mathrm{m} / \mathrm{s})$ & 7.37 & 10.97 & 9.26 & 8.40 & 8.13 \\
\hline $\mathrm{SFC}(\mathrm{lbs} /(\mathrm{lbsf} \cdot \mathrm{h}))$ & 0.565 & 0.576 & 0.576 & 0.545 & 0.620 \\
\hline
\end{tabular}

Figures 9 and 10 provide graphical representations for the takeoff run and the climb rate:

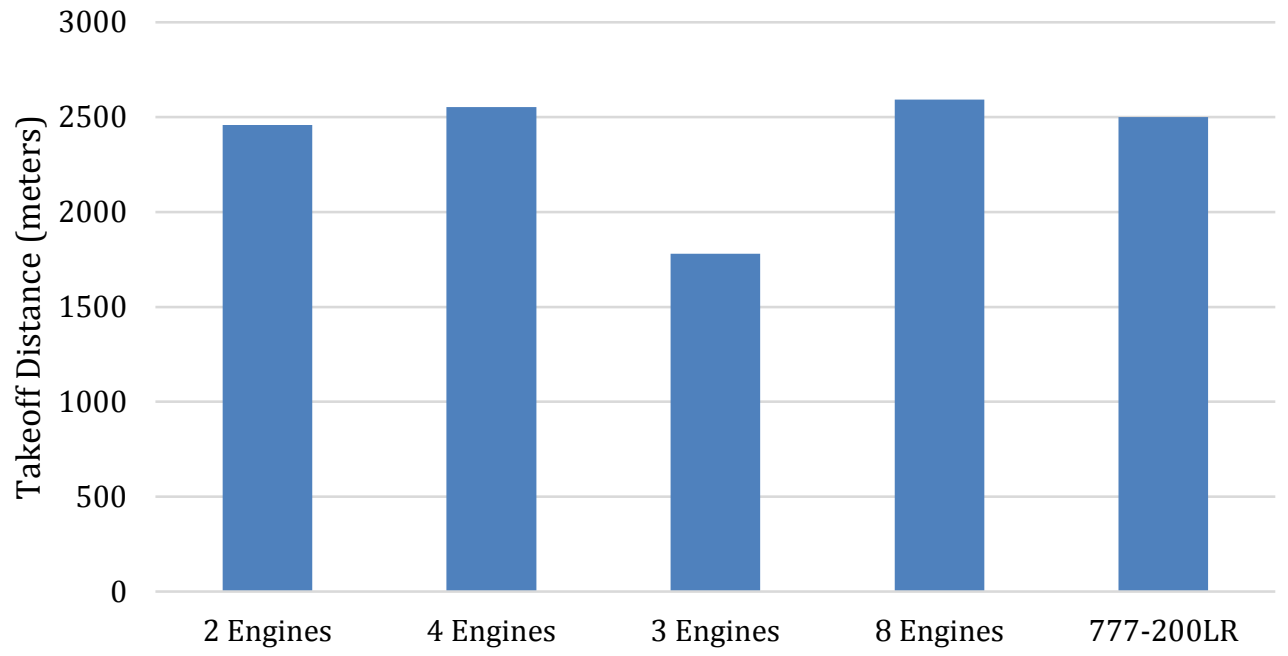

Figure 9. Takeoff distances for all BWBs and the 777-200LR. No derate. 


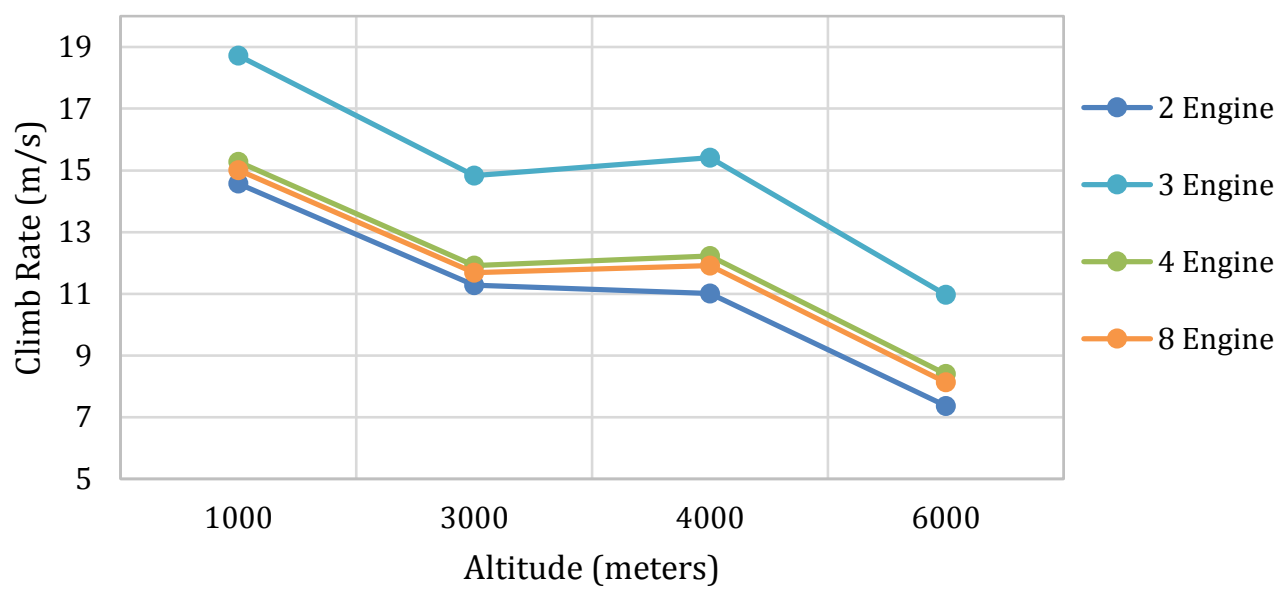

Figure 10. Climb rate as a function of altitude for all configurations. No derate.

The three-engine case model presented a problem. All engines of satisfactory performance were very old (1970s era). As a result, they had poor SFC performance. Two examples are the JT9D-20, which gives a good takeoff run of 2,322 meters for 46,300 pounds thrust per engine, and the JT9D-3A, with a takeoff run of 2,630 meters for 44,250 pounds of thrust per engine. These are the engines used in the DC-10 and the 747-100. The lack of new aircraft engines with the required thrust range is likely due to the recent two-engine configuration trend embraced by most large jetliners. Thus, an engine with greater-than-needed thrust, but improved SFC and other characteristics was chosen. The General Electric CF6$80 \mathrm{C} 2 \mathrm{~A} 2$ was the engine selected; a $10 \%$ derate would give it characteristics similar to that of the two-engine case.

Figure 11 on the next page shows the final six BWB models that will be compared; the wing was created earlier from the planform and airfoil selection. Data such as fan diameter and engine width allow for the creation of an accurate CAD model as the engines are selected. Note that for the creation of the PS-7, the fan diameter is estimated from another Solovyev engine 


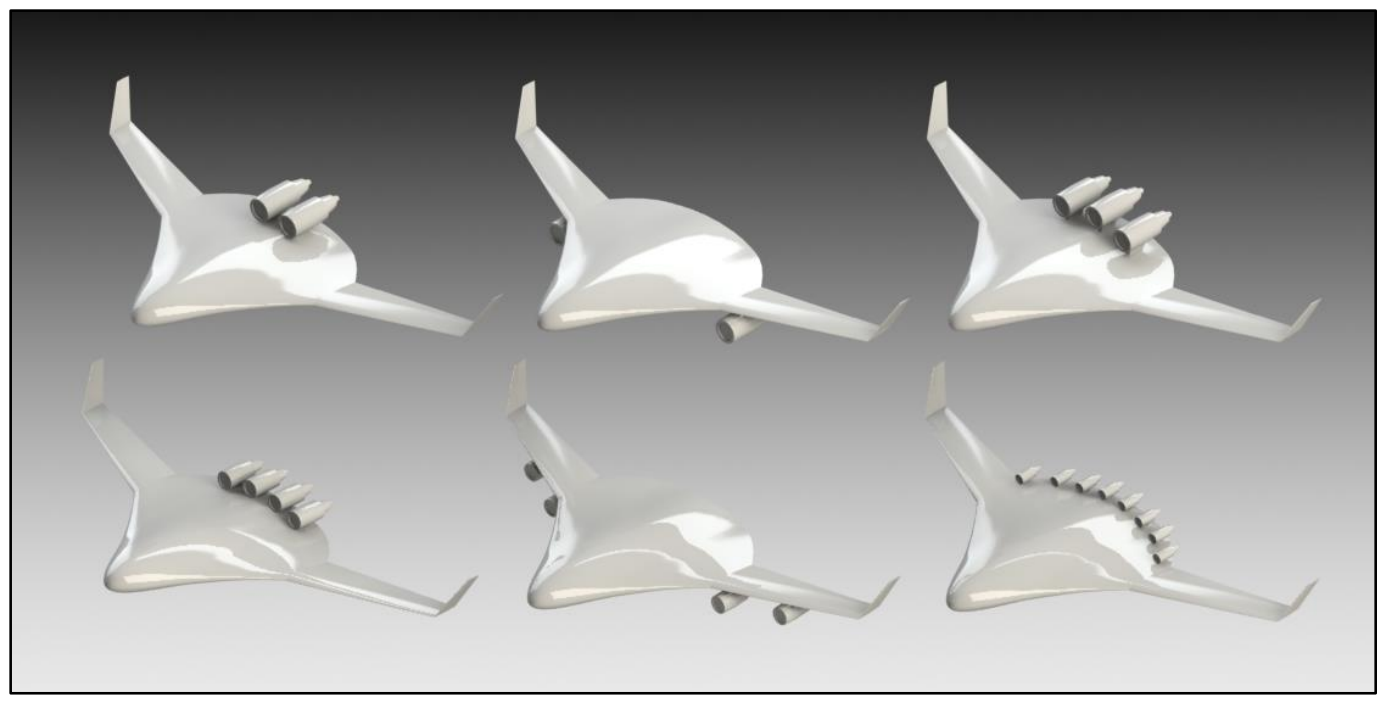

Figure 11. CAD rendering of all 6 models.

\section{Miscellaneous Computations}

This study also considers different parameters for different configurations, which are shown below. Table 8 shows the actual values for these configurations.

\section{Zero Lift Drag Coefficient}

Van Es and Gerard (2002) show that the zero lift drag coefficient can be more accurately written as

$$
C_{d 0}=C_{f e} *\left(\frac{S_{w e t}}{S_{r e f}}\right)
$$

They also find that

$$
C_{f e} \approx 0.00258+0.00102 * e^{-6.28 * 10^{-9} R E}+0.00295 * e^{-2.01 * 10^{-8} R E}
$$

Where the Reynolds Number can be expressed as

$$
R E=\frac{\left(\frac{S_{w e t}}{b}\right) V}{v}
$$

Where in this case, $V$ is velocity and $v$ is kinematic viscosity. From here, we find the zero lift drag coefficients from known data. $S_{w e t}, S_{r e f}$ and $b$ are all measured from the CAD model, and the remainder of variables are found from flight conditions. 


\section{Empty Weight \& Approximate Maximum Takeoff Weight (MTOW)}

Our initial estimation had previously used

$$
W_{\text {prop }}=\frac{\text { TOW }}{15}=41,047 \mathrm{lbs} .
$$

Now that we have the actual weights of the engines, we can use that data and the equation

$$
W_{\text {prop }}=1.6 * W_{d r y}
$$

to compute a more accurate value of the empty weight.

We can also compute the MTOW of the aircraft by setting the takeoff distance equal to 3,000 meters, which is approximately the takeoff run of the Boeing 777-200LR at MTOW and sea level (Boeing, 2015). We conduct a sample calculation for the two-engine model-the process is identical for the other three cases.

We still have the following equations:

$$
\begin{aligned}
& S=\int_{0}^{v_{f}} \frac{W}{g} * \frac{v}{(T-D-0.02(W-L))} d v \\
& T_{M}=T_{0}+\frac{v}{332 * M_{c}} *\left(T_{c} *\left(\frac{\rho_{0}}{\rho_{c}}\right)^{0.9}-T_{0}\right)
\end{aligned}
$$

We know that

$$
M_{c} \approx 0.825, \rho_{c}=0.825
$$

Additionally,

$$
C_{d}=C_{d 0}+C_{d i}=C_{d 0}+\frac{C_{L}^{2}}{\pi A R e}
$$

Using the zero lift drag coefficient computed earlier we have

And also

$$
C_{D} \approx 0.234
$$

$$
V_{\text {takeoff }}=1.2 * V_{\text {stall }}=1.2 * \sqrt{\frac{2 * W}{\rho S C_{\text {Lmax }}}}=0.12277 \sqrt{\frac{W}{g}}
$$


Substituting all of the above we have the following equation:

$$
3000=\int_{0}^{v_{f}} \frac{m * v}{\left(632,505-1238.18 v-0.02 * m g-90.9011 v^{2}\right)}
$$

We solve this with a numerical solver for mass, finding that the max takeoff weight is about 305,000 kilograms for this two-engine configuration.

\section{Drag Coefficient Calculation-Cruise Flight}

While we cannot compute the exact drag coefficient due to all factors (such as wave drag, interference drag, etc.), we may compute an approximate value. Looking at only zero-lift drag and induced drag, we have that

$$
C_{d}=C_{d 0}+C_{d i}=C_{d 0}+\frac{C_{L}^{2}}{\pi A R e}
$$

Note that the induced drag coefficient is constant between models; only the zero lift drag coefficient changes, due to the change in the wetted surface area. At cruise flight the weight of the aircraft varies considerably. We will consider the weight about halfway through flight. This would be approximately $230,000 \mathrm{~kg}$, from previous weight calculations, and then we can solve for lift coefficient then as during cruise as lift must counterbalance the weight. Substituting known values for the rest, we have

$$
\begin{gathered}
C_{d i}=\frac{C_{L}^{2}}{\pi A R e}=\frac{2 m g}{\rho v^{2} S * \pi A R e}=\frac{2 m g}{0.36 * 250^{2} * \pi * e * 5.87}=0.01496 \\
C_{d}=C_{d 0}+C_{d i}=C_{d 0}+0.01496
\end{gathered}
$$

The Data Summary section contains all data from evaluating equations.

\section{CFD Analysis}

Computational Fluid Dynamics (CFD) analysis provides additional data on the lift and drag of the BWBs. Theoretically, all configurations should produce approximately the same amount of lift, due to the wing commonality. Therefore, the majority of lift differences would occur due to airflow disruption near the engines. Thus, CFD gives us the ability to conduct some comparison of interference effects of different engine configurations. The solver used is SolidWorks CFD. CFD Validation with the software shows that lift is generally near the actual value, and drag is often significantly overestimated. Despite this, the data is still valuable 
for relative comparisons. Each model was tested at a five-degree angle of attack. The following section shows the data results. Two flow trajectories can be found in the data analysis section as well.

\section{Data Summary}

Table 8

All Data Summary-BWB \& 777-200LR. Data from Boeing, 2008; Boeing, 2015; and Meier, 2005

\begin{tabular}{|c|c|c|c|c|}
\hline Configuration & $\begin{array}{l}2 \text { Engine } \\
\text { Aft }\end{array}$ & $\begin{array}{l}2 \text { Engine } \\
\text { Under }\end{array}$ & 4 Engine Aft & $\begin{array}{l}4 \text { Engine } \\
\text { Under }\end{array}$ \\
\hline Lift (lbs. f) & 503,100 & 546,366 & 406,643 & 459,446 \\
\hline Drag (lbs. f) & 135,861 & 160,755 & 120,886 & 152,714 \\
\hline Lift/Drag & 3.70 & 3.40 & 3.36 & 3.01 \\
\hline$C_{d}$ & 0.02131 & 0.02129 & 0.02138 & 0.02139 \\
\hline MTOW* (lbs) & 672,410 & 672,410 & 665,796 & 665,796 \\
\hline Empty Weight (lbs.) & 294,673 & 294,673 & 297,393 & 297,393 \\
\hline Engine Name & $\begin{array}{l}\text { RR Trent } \\
772-60\end{array}$ & $\begin{array}{l}\text { RR Trent } 772- \\
60\end{array}$ & CFM56-5C4 & CFM56-5C4 \\
\hline $\begin{array}{l}\text { Engine Thrust (lbs. } \\
\text { f) }\end{array}$ & 71,100 & 71,100 & 34,000 & 34,000 \\
\hline Total Thrust (lbs. f) & 142,200 & 142,200 & 136,000 & 136,000 \\
\hline SFC $(\mathrm{lbs} /(\mathrm{lbsf} \cdot \mathrm{h}))$ & 0.565 & 0.565 & 0.545 & 0.545 \\
\hline T/W (MTOW) & 0.211 & 0.211 & 0.204 & 0.204 \\
\hline T/W (Empty) & 0.483 & 0.483 & 0.457 & 0.457 \\
\hline Takeoff Run^ $(m)$ & 2458 & 2458 & 2554 & 2554 \\
\hline $\begin{array}{l}\text { Climb Rate-1000 m } \\
(\mathrm{m} / \mathrm{s})\end{array}$ & 14.57 & 14.57 & 15.28 & 15.28 \\
\hline $3000 \mathrm{~m}(\mathrm{~m} / \mathrm{s})$ & 11.28 & 11.28 & 11.92 & 11.92 \\
\hline $4000 \mathrm{~m}(\mathrm{~m} / \mathrm{s})$ & 11.01 & 11.01 & 12.23 & 12.23 \\
\hline $6000 \mathrm{~m}(\mathrm{~m} / \mathrm{s})$ & 7.37 & 7.37 & 8.40 & 8.40 \\
\hline
\end{tabular}


Table 8 (continued)

All Data Summary-BWB \& 777-200LR. Data from Boeing, 2008; Boeing, 2015; and Meier, 2005

\begin{tabular}{lccc}
\hline Configuration & 3 Engines Aft & 8 Engines Aft & 777-200LR*** \\
\hline Lift (lbs. f) & 392,703 & 501,291 & - \\
Drag(lbs. f) & 146,846 & 104,139 & - \\
Lift/Drag & 2.67 & 4.77 & - \\
$C_{d}$ & 0.02159 & 0.02113 & Unavailable \\
MTOW* (lbs) & 744,060 & 664,694 & 766,000 \\
Empty Weight (lbs.) & 305,841 & 299,005 & 320,000 \\
Engine Name & CF6-80C2A2 & Solovyev PS-7 & GE90-110B1 \\
Engine Thrust (lbs. f) & 52,460 & 17,000 & 110,000 \\
Total Thrust (lbs. f) & 157380 & 136,000 & 220,000 \\
SFC (lbs/(lbsf·h)) & 0.578 & 0.620 & $0.50-0.55 * *$ \\
T/W (MTOW) & 0.212 & 0.205 & 0.287 \\
T/W (Empty) & 0.515 & 0.455 & 0.688 \\
Takeoff Run^(m) & 1781 & 2592 & $\sim 2500$ \\
Climb Rate-1000 m & 18.72 & 15.01 & Unavailable \\
(m/s) & 14.83 & 11.69 & Unavailable \\
3000 m (m/s) & 15.41 & 11.91 & Unavailable \\
4000 m (m/s) & 10.97 & 8.13 & Unavailable \\
6000 m (m/s) & & & \\
\hline
\end{tabular}

*MTOW calculations assume requirement of takeoff in 3000 meters-structural issues not studied.

** Data Unavailable and approximated from other GE90 engines. Good approximation would be 0.545 (GE90-76B) or 0.520 (GE90-85B).

***Lift, Drag, and Lift/Drag are not calculated for the 777-200LR, as a model was not made and tested in SolidWorks CFD. An extension of this project would be to do so in order to be able to do proper aerodynamic comparison between the BWB and the 777200LR.

${ }^{\wedge}$ When carrying full passenger load and fuel for $9380 \mathrm{nmi}$. flight. 777-200LR value approximated from data given by Boeing (2015) 


\section{Data Analysis}

Table 8 and Figure 12 show the BWB with eight engines has the greatest aerodynamic performance; it has a lift to drag ratio of 4.77 , which is significantly greater than that of the other models.

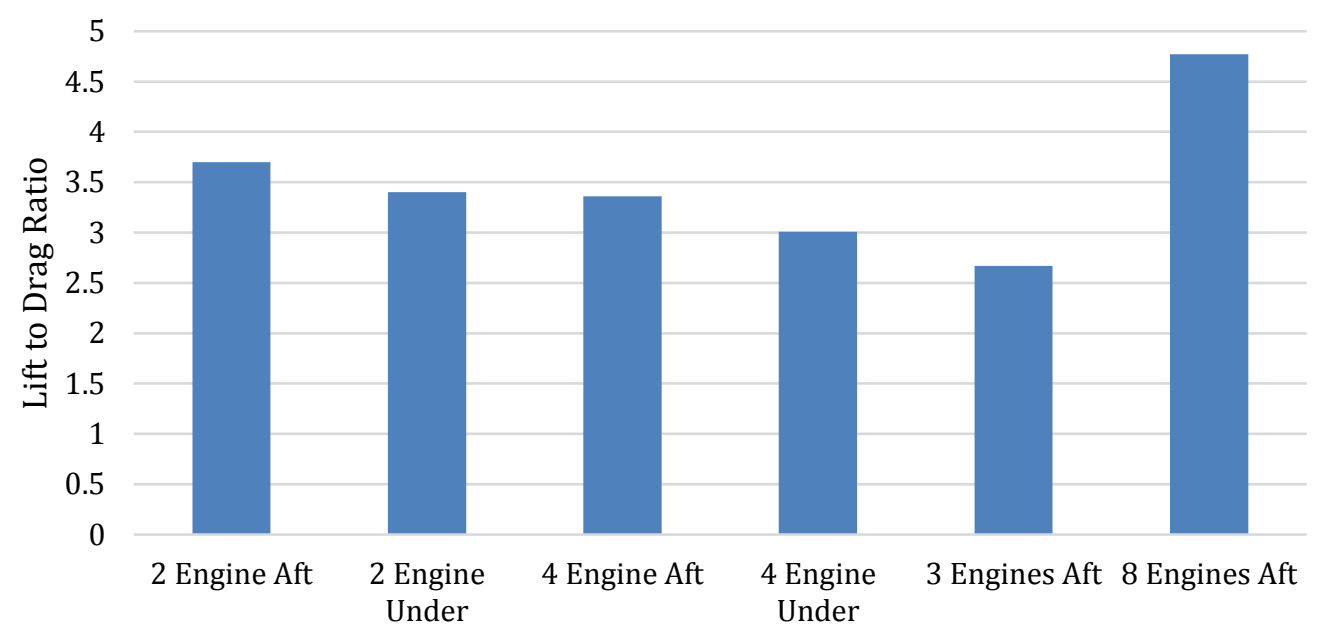

Figure 12. Lift to drag ratio of the various BWB configurations.

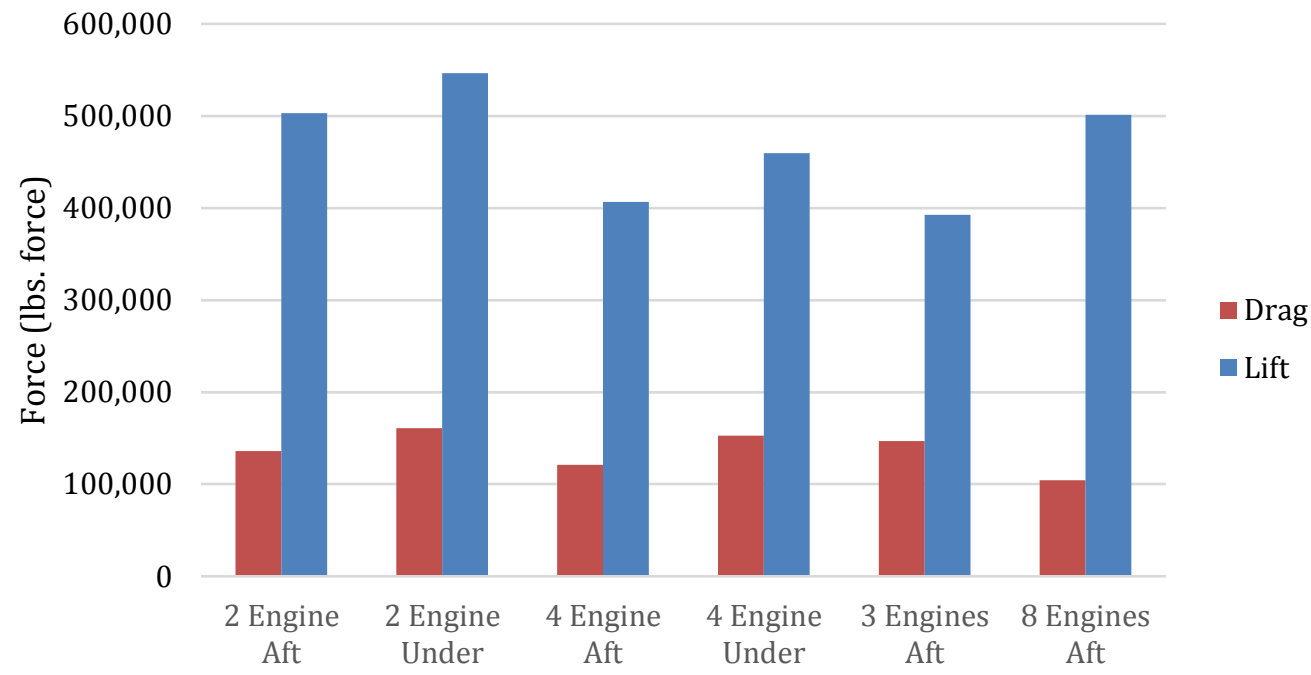

Figure 13. Lift and drag of the various BWB configurations.

In Figure 13 above, we can see that the distributed eight-engine design has approximately $86 \%$ of the drag of the next best configuration; this substantial difference shows the significance of interference drag. The interference drag differences can also be seen visually in Figure 14 and 15. Note that the airflow 
behind the engines is significantly less turbulent for the eight-engine design compared to the two-engine design. Since all aircraft were tested at the same angle of attack and had the same overall airframe, the differences in the aerodynamic factors were entirely due to the propulsion system.

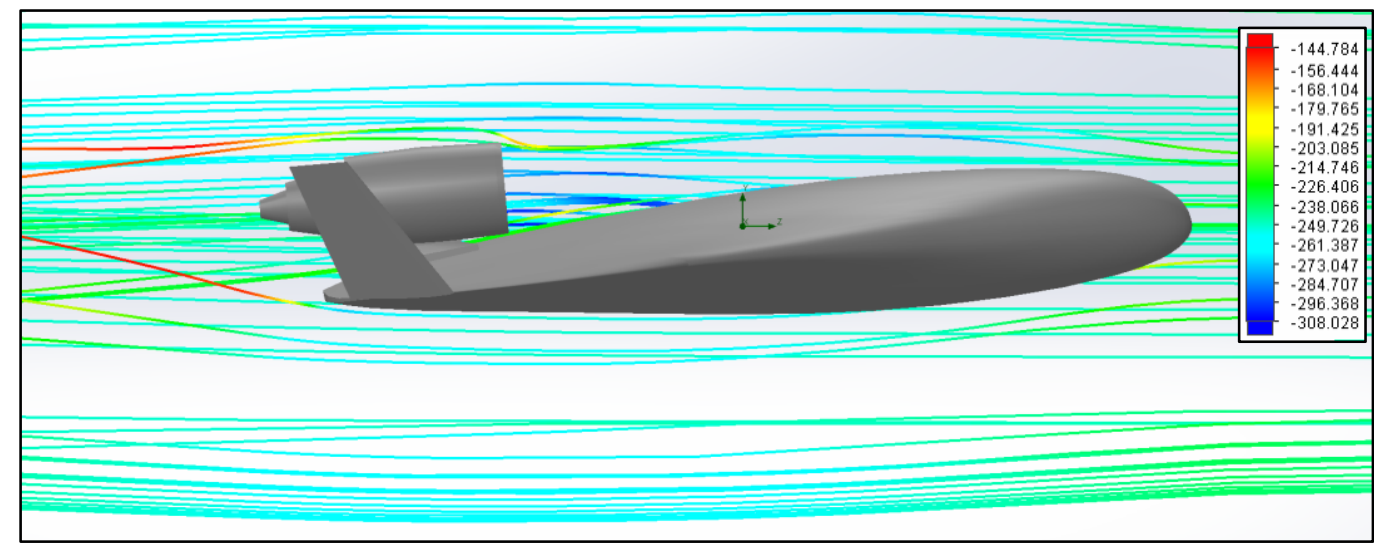

Figure 14. Flow trajectory for two-engine configuration.

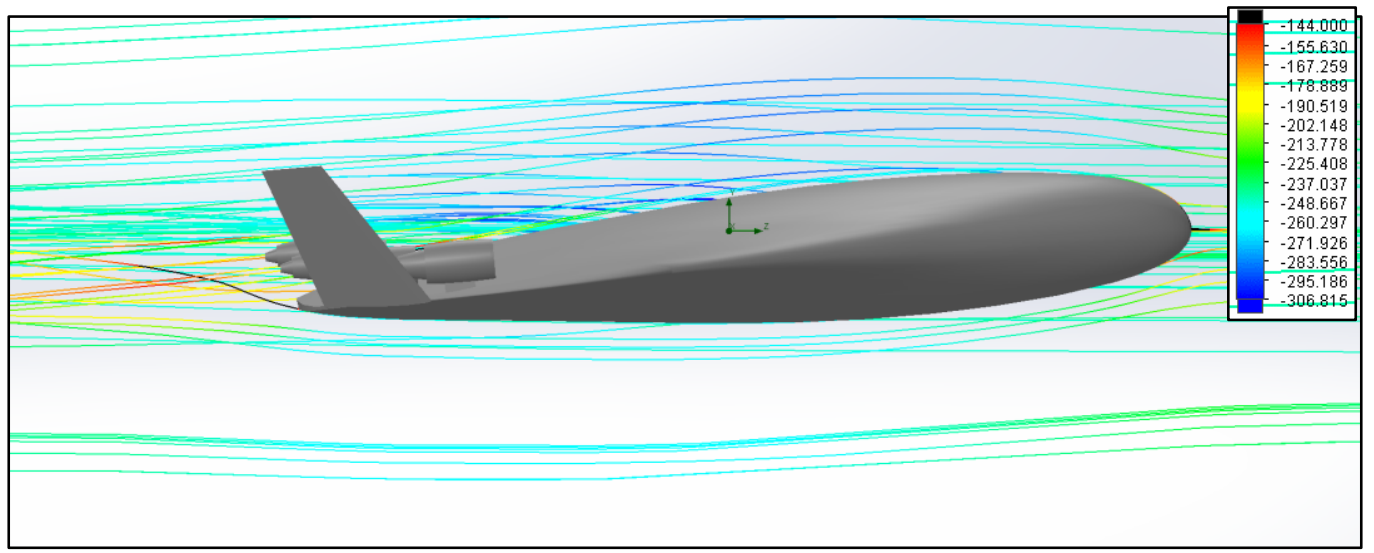

Figure 15. Flow trajectory for eight-engine configuration. Color scaling is very similar to that of Figure 14. Black lines symbolize flows below $144 \mathrm{~m} / \mathrm{s}$.

Figure 13 also shows that the three-engine configuration and both of the four-engine configurations produce less lift than the two and eight-engine configurations. Furthermore, the aft engine cases produce markedly less lift than the matching underwing case. Despite this, the aft engine cases generally did better than the underwing cases aerodynamically, due to significantly decreased drag. This can be seen with the two and four-engine configurations; the underwing mounted configuration had around 50,000 lbs. greater lift both times, despite having a lower lift to drag ratio. 
There are several potential reasons for the aerodynamic factors we have seen. For all of the aft mounted configurations, the engines are disrupting the airflow at the trailing edge of the center body airfoil. This produces a significant portion of the total lift (having the largest chord). This is likely the main reason for the reduction in lift. Despite this, all of the configurations with engines underneath, while having greater lift, have a significant drag penalty since the engines disrupt the elliptical distribution of lift to a great extent, producing significant turbulence. As expected, the three-engine aircraft performed the worst aerodynamically (mainly because of the largest wetted area of the engines and the largest theoretical drag coefficient (0.02159)), and the eight-engine the best, due to the smaller engine size, minimizing airflow disruption and flow separation.

Figure 16 shows that the empty weights of the models are similar, and as expected, the eight-engine configuration is slightly higher than the rest (excluding

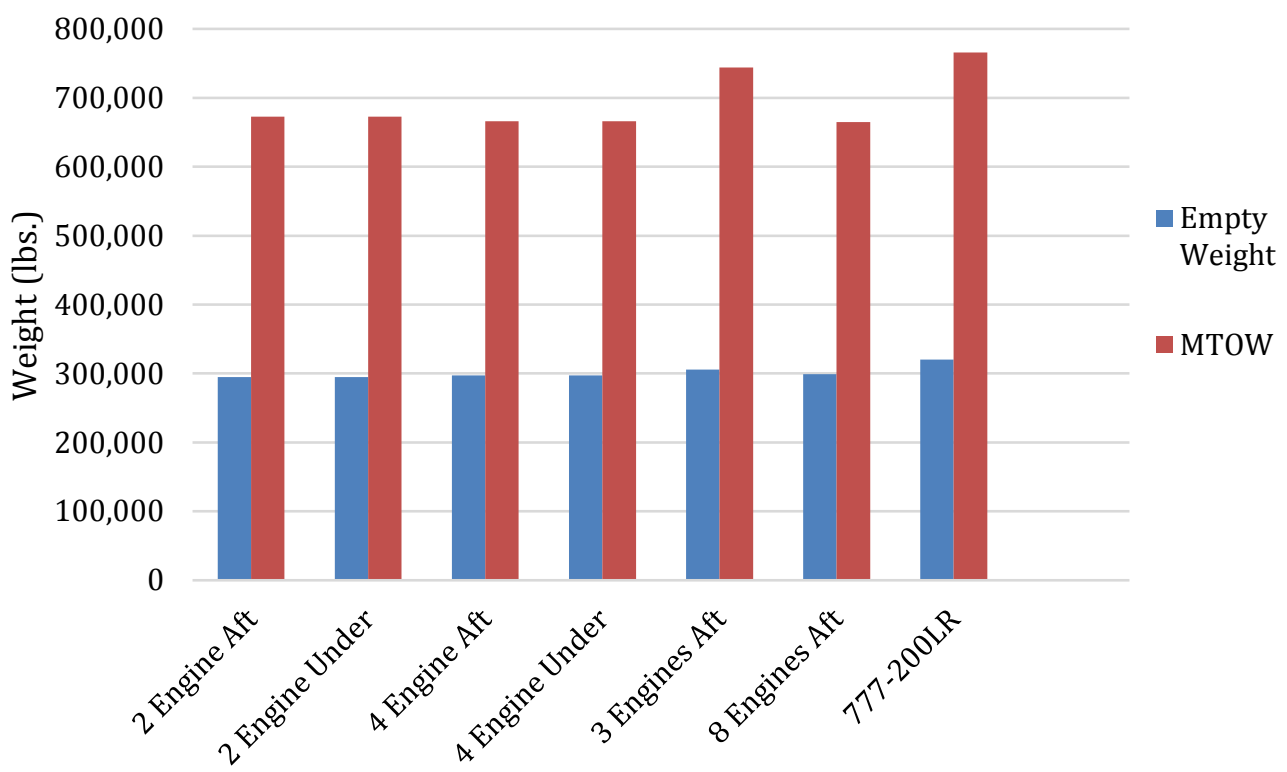

Figure 16. Empty weights and MTOW of the models.

the three-engine model, which has higher thrust to compensate). The BWBs also have a lower empty weight than the 777-200LR. Beyond empty weight, the increased thrust of the model with three engines allows it to have significantly greater max takeoff weight - very close to that of the 777-200LR. Combined with the fact that the three-engine model has slightly lower empty weight when compared with the 777 , it likely will have similar maximum payload capacity. The MTOWs of the other designs, however, are nearly 100,000 lbs. less than that of the 
777-200LR. In order for these BWBs to maintain both the range and payload of the 777 , it would be necessary for the aircraft to have significantly less fuel consumption (corresponding to lower required fuel weight).

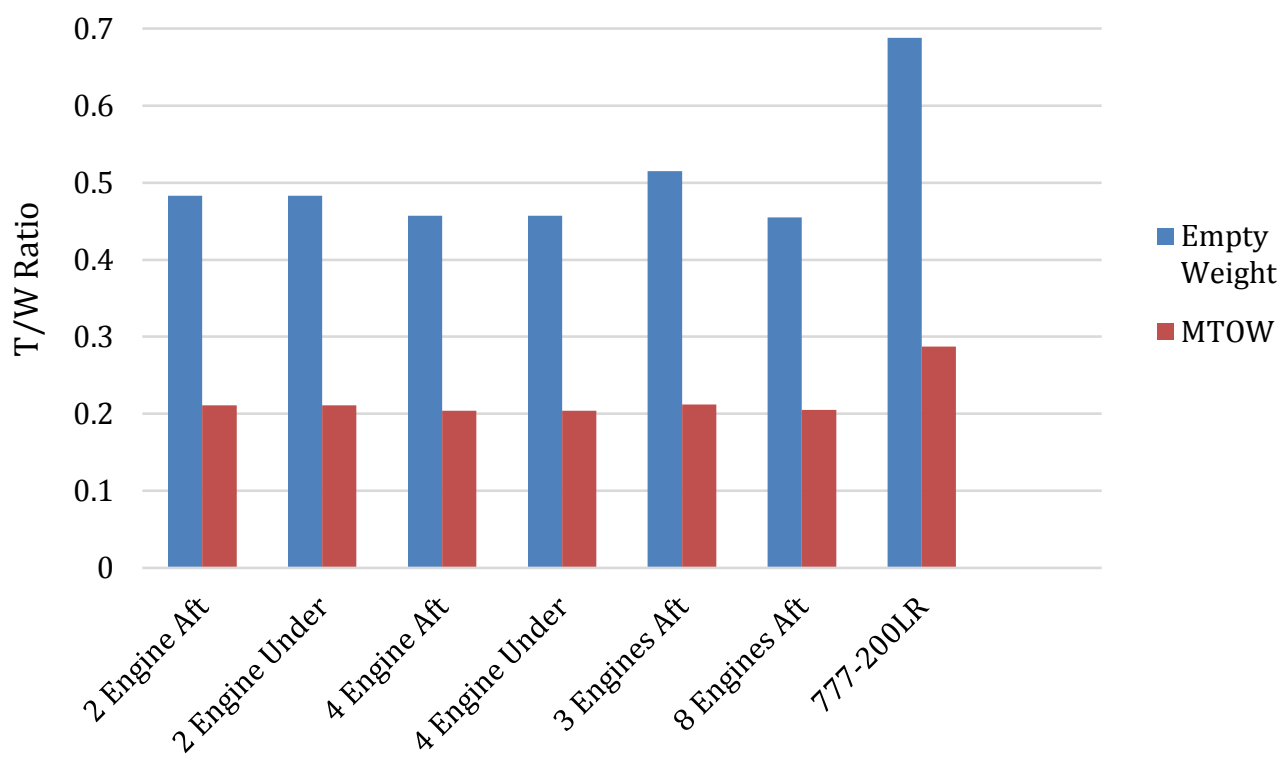

Figure 17. Max Thrust to weight ratio when empty and when at MTOW for all configurations.

Figure 17 shows the variation of thrust to weight ratio among the different configurations. Interestingly, every BWB has a lower thrust to weight ratio than the 777-200LR. For an aircraft, lower T/W is optimal, as it leads to decreased thrust and therefore decreased fuel consumption. This is likely the result of the low stall speed (which itself came from greater wing area/more lift production), which leads to the aircraft being able to get airborne more quickly. As a result, the aircraft needs less thrust for takeoff, the main stage of flight where engines are being used at full throttle.

Regarding the cruise-specific fuel consumption of each aircraft, the eightengine configuration clearly has a much higher value, which can be seen in Figure 18. It is important to note that the Trent 772 used in the two-engine configurations is moderately newer than the rest; thus, it would be expected that more modern engines with comparable thrust values could be substituted for the three, four, and eight-engine configurations respectively, and that those SFCs may be lower afterwards (a lack of data on newer engine designs prevent their use for those cases). This perhaps can bring the three-engine configuration's SFC in line with the 
two-engine configuration, and can further improve the four-engine's advantage over the rest. However, the eight-engine configuration may not be able to close this gap, even with a newer design. This can be attributed to the fact that such small engines are primarily used on smaller domestic aircraft. These aircraft experience a large portion of their fuel consumption during takeoff, climb, descent, and landing. In contrast, the proposed long range BWB spends a much smaller fraction of its fuel during the takeoff, landing, climb, and descent phases, and cruise performance is much more important. Thus, in general smaller engines are not as optimized for very long-range missions. If distributed aircraft propulsion designs gain popularity, new engine technology will be required to resolve this issue.

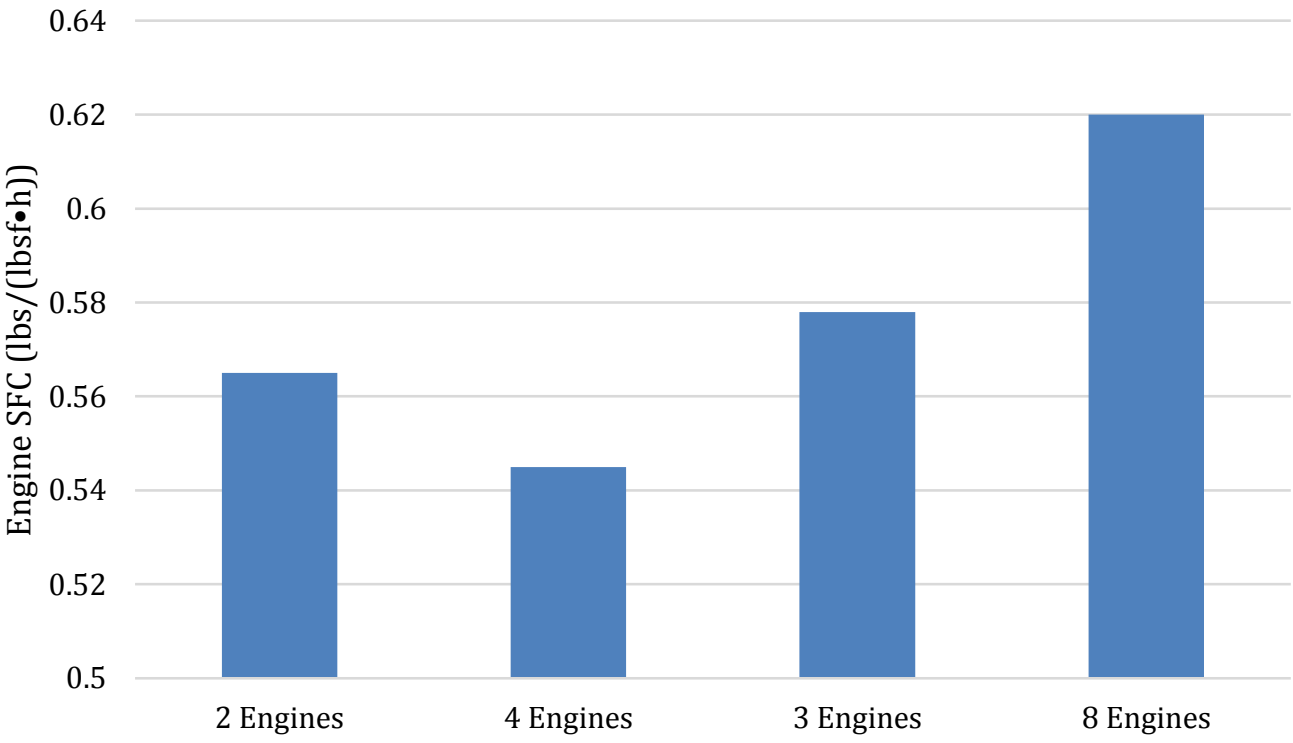

Figure 18. SFC values for engines used in various configurations.

After careful analysis of the aforementioned data in the tables and figures above, it remains unclear which engine configuration is optimal for a BWB design. The eight-engine model is superior in aerodynamic performance, the three-engine is ideal for MTOW, the two-engine cases have optimal empty weight, and the fourengine configuration is deal for SFC.

Furthermore, while the aft engine cases have superior aerodynamic performance, the reduced lift during zero-degree angle of attack cruise flight could make it difficult to fly near MTOW without a large angle of attack. The distributed design of the eight-engine would likely require greater initial design work, especially to overcome the high SFCs of similar thrust engines, but may yield higher rewards in the end. Conversely, the two-engine aft configuration performs 
well in every category - not just aerodynamics - and would likely require less design work due to good initial engine performance.

The results of the research above did not produce enough conclusive evidence to make a definitive statement regarding ideal engine placement. However, it does suggest that optimal engine placement would be in the aft of the aircraft due to the significant increase in drag caused by under-wing engine placement. Similarly, the three- and four-engine designs may not be optimal for fuel efficiency due to the fact that they combine the disadvantages of both the twoand eight-engine designs - a larger disruption to the airflow than the eight-engine configuration and an airflow disturbance over a larger portion of the wing than the two-engine configurations - without having much of the benefits.

Ideally, we would be able to compute the actual fuel consumption of each aircraft configuration along a set circuit. This could potentially be done with the Breguet Range Equation

$$
R=M * \frac{a}{S F C} * \frac{L}{D} * \ln \left(\frac{W_{0}}{W_{1}}\right)
$$

where $a$ is the speed of sound, $M$ is the cruise Mach, $W_{1}$ is the zero-fuel weight, and $R$ is the range. We can write $W_{0}=W_{1}+W_{f}$, where $W_{f}$ is the amount of fuel consumed. From here we can solve for $W_{f}$ to find that

$$
W_{f}=W_{1}\left(e^{\frac{R}{M} * \frac{S F C}{a} * \frac{D}{L}}-1\right)
$$

Unfortunately, we do not have an absolutely accurate value of the lift to drag ratio, as SolidWorks is only a low fidelity CFD software, providing only trends; therefore, we do not calculate this value.

\section{Conclusions}

This research revealed that the distributed propulsion design with eight engines had the greatest lift to drag ratio and aerodynamic performance at the cost of slightly greater empty weight and lower MTOW than the other designs. Most significantly and problematically, the distributed design had a high SFC. The issue of balancing aerodynamic performance, engine performance, and weight characteristics correctly in aircraft is visible in this project - no single BWB propulsion system configuration is ideal in all parameters. However, overall, we 
believe that a distributed propulsion system for a passenger BWB likely holds the most promise for the future, especially since it has the most room to grow with new technology, and already holds excellent performance parameters. With current technology, both the two- and eight-engine designs hold promise. Furthermore, we have identified several areas of research that may benefit the eight-engine distributed propulsion BWB greatly, and these are mentioned in the final paragraph.

The limitations to this study stem primarily from three different areas. The first significant one is the CFD tool; the lower fidelity tool prevents us from comparing the lift to drag ratios beyond a relative comparison within our data set. To alleviate this problem, we recommend utilizing a higher fidelity CFD software (such as ANSYS Fluent), wind tunnel testing, and designing a model of the 777. Therefore, we could make direct comparisons between the current paradigm and the BWB in addition to obtaining an absolute value of the lift to drag ratio, allowing us to compute a relatively accurate value of fuel consumption for the different models.

Secondly, the propulsion system design was made from engines that currently exist, rather than ones that can be designed. While this was the intent of the study, it also poses a limitation on the available design space, especially because few long-range aircraft engines are being designed with the low thrust required for distributed propulsion. This is the reason for the poor SFC in the eight-engine design, as in short range, low thrust engines cruise SFC is less important. If we extend our design space into the realm of what can be designed, rather than what already exists, it is likely that the eight-engine design will improve significantly.

Furthermore, advances in materials (especially composites) have rendered many conventional systems design weight formulas less effective, and any future BWB would certainly be composed at least partially from these advanced materials. To correct for this, it would be necessary to conduct a significantly more detailed weight analysis, one that could even be its own paper. It would be necessary to develop regressions and surrogate models for composites, then combine them with conventional preliminary weight estimation tools. This limitation is perhaps the one that affects the results the most. Composite materials would likely reduce the empty weight of the aircraft by an appreciable amount, and allow for perhaps lower thrust engines or higher performance with the current set.

We recommend several future studies. The first is a study on designing more efficient low thrust engines. This would significantly improve the feasibility of the eight-engine BWB. Secondly, a detailed weight analysis considering composite materials and their application onto BWBs would be beneficial. Lastly, there are 
several new technologies still being developed, such as boundary layer ingestion (briefly mentioned in the literature review), that can be used to optimize the distributed propulsion design further. Many papers have been published on this topic, but the vast majority are simply conducting an analysis on a single engine. A dedicated paper on a boundary layer ingesting propulsion system and its integration with the rest of the aircraft would be a valuable addition to the current body of research. 


\section{References}

Boeing Commercial Airplanes. (1999). 777 flight crew training manual. Seattle, WA: Author.

Boeing Commercial Airplanes. (2015). 777 airplane characteristics for airport planning: Revision E, Seattle, WA: Author. Retrieved from http://www.boeing.com/assets/pdf/commercial/airports/acaps/777_2lr3er.p df

Bradley, K. R. (2004). A sizing methodology for the conceptual design of blended wing body transports. NASA TM-2004-213217. Retrieved from https://ntrs.nasa.gov/archive/nasa/casi.ntrs.nasa.gov/20040110949.pdf

Djojodihardjo, H., \& Wei, A. (2012). Conceptual design and aerodynamic study of blended wing body business jet. Paper presented at the $28^{\text {th }}$ International Congress of the Aeronautical Sciences. doi: 10.13140/2.1.2478.1122

Dommelen, J., \& Vos, R. (2012). A conceptual design and analysis tool for blended wing body aircraft. Paper presented at the $28^{\text {th }}$ International Congress of the Aeronautical Sciences. Retrieved from http://www.icas.org/ICAS_ARCHIVE/ICAS2012/PAPERS/454.PDF

Hanlon, C. J. (2003). Engine design implications for a blended wing body aircraft with boundary layer ingestion. (Master's Thesis). Retrieved from https://dspace.mit.edu/bitstream/handle/1721.1/82759/54069199-MIT.pdf

Ko, A., Leifsson, L. T., Mason, W. H., Schetz, J. A., Grossman, B., \& Haftka, R. T. (2003). MDO of a blended wing body transport aircraft with distributed propulsion. Paper presented at the AIAA $3{ }^{\text {rd }}$ Annual Aviation Technology, Integration, and Operations Forum.

doi: $10.2514 / 6.2003-6732$

Kroo, I. Aircraft design: Synthesis and analysis (Desktop Aeronautics Inc., Version 0.9). Stanford, CA: Stanford University.

Liebeck, R. H. (2003). Blended wing body design challenges. Paper presented at the AIAA International Air and Space Symposium. doi: 10.2514/6.2003-2659 
Liebeck, R. H. (2004). Design of the blended wing body subsonic transport. Journal of Aircraft, 41(1), 10-25.

doi: $10.2514 / 1.9084$

Meier, N. (2005). Jet engine specification database. Retrieved from http://www.jet-engine.net/civtfspec.html.

Nickol, C. L. (2012). Hybrid wing body configuration scaling study. Paper presented at the $50^{\text {th }}$ AIAA Aerospace Sciences Meeting. AIAA.

Washington, DC.

doi: $10.2514 / 6.2012-337$

Nickol, C. L., and McCullers, L. A. (2009). Hybrid wing body configuration system studies. Paper presented at the 47th AIAA Aerospace Sciences Meeting. doi: $10.2514 / 6.2009-931$

Oates, G. C. (ed.). (1989). Aircraft propulsion systems technology and design, AIAA Education Series. Washington, DC: AIAA.

Potsdam, M., Page, M., and Liebeck, R. H. (1997). Blended wing body analysis and design. Paper presented at the AIAA $15^{\text {th }}$ Applied Aerodynamics Conference. doi: $10.2514 / 6.1997-2317$

Qin, N., Vavelle, A., Le Moigne, A., Laban, M., Hackett, K., and Weinerfelt, P. (2004). Aerodynamic considerations of blended wing body aircraft. Progress in Aerospace Sciences, 40(6), 321- 343. doi: 10.1016/j.paerosci.2004.08.001

Roman, D., Allen, J., and Liebeck, R. (2000). Aerodynamic design challenges of the blended wing body subsonic transport. Paper presented at the AIAA $18^{\text {th }}$ Applied Aerodynamics Conference.

doi: $10.2514 / 6.2000-4335$

Trani, A. A. (n.d.). Detailed example of aircraft performance: Calculations: Climb performance. Virginia Tech Air Transportation Systems Laboratory: CEE 5614 [online class resource]. Retrieved from http://128.173.204.63/courses/cee5614/cee5614_pub/examples_aircraft_p erf_1.pdf 
Kumar and Khalid: Blended Wing Body Propulsion System Design

Van Es. Gerard W. H. (2002). Rapid estimation of the zero lift-drag coefficient of transport aircraft. Journal of Aircraft, 39(4), 597-599.

doi: $10.2514 / 2.2997$ 


\section{Appendix}

\section{Neutral Point Computation: Related Formulas}

The function for change in chord with respect to span $C(y)$ is

$$
C(y)=\begin{array}{cc}
-1.5402 y+31.698, & 0<y<6.559 \\
-1.8056 y+33.439, & 6.559<y<8.745 \\
-2.1199 y+36.188, & 8.745<y<13.548 \\
-0.208 y+10.286, & 13.548<y<31.352
\end{array}
$$

Where we are ignoring angle of incidence effects, which are generally minimal (largest angle of incidence in this case was only 1.4 degrees)

The function for change in quarter chord location with respect to the front of the aircraft, $D_{Q}(y)$, is

$$
\begin{array}{cc}
1.054 y+7.9245, & 0<y<6.559 \\
0.9887 y+8.3533, & 6.559<y<8.745 \\
0.6805 y+11.048, & 8.745<y<13.548 \\
0.4297 y+14.446, & 13.548<y<31.352
\end{array}
$$

Both equations were found from measurements of the top view of the aircraft.

\section{Neutral Point Computation}

Let $C_{1}, C_{2}, C_{3}, C_{4}, C_{5}$, and $C_{6}$ represent the lift coefficients for the airfoil section 0 meters from the center, 6.559 meters from the center, 8.745 meters from the center, 13.548 meters from the center, 26.5 meters from the center, and 31.352 meters from the center, respectively. Assuming we are conducting analysis for relatively low angles of attack (less than 8 degrees), where a plane might cruise, we can assume that all airfoil sections are in the linear region of the lift curve.

Thus, we can express all of those six lift coefficients as $C_{i}=k_{i}\left(\alpha_{i}+\alpha\right)+$ $b_{i}$, for $i$ is from 1 to 6 , with $k_{i}$ being the lift curve slope of the airfoil section, $a_{i}$ being the angle of incidence, $b_{i}$ being the zero angle of attack lift coefficient, and lastly, $\alpha$ being the angle of attack of the plane.

As the wing is made by lofting together six airfoil sections, we make the approximation that the lift coefficient of any airfoil section between two others is 
going to be the weighted average of the lift coefficients of the others, with the weights depending upon distance between them. For example, the lift coefficient of the section 3.2795 meters from the center will be $\frac{C_{1}+C_{2}}{2}$, as it is half way to 6.559 meters, while the lift coefficient of the section 1.639 meters from the center will be $\frac{1.5 * C_{1}+.5 * C_{2}}{2}$, as it is only $25 \%$ of the way to the second airfoil section.

$$
\begin{gathered}
C_{1} *\left(1-\frac{y}{6.559}\right)+C_{2} *\left(\frac{y}{6.559}\right) \\
C_{2} *\left(1-\frac{y-6.559}{8.745}\right)+C_{3} *\left(\frac{y-6.559}{8.745}\right)
\end{gathered}
$$

Thus, we can write that $C_{L}(y)=C_{3} *\left(1-\frac{y-8.745}{13.548}\right)+C_{4} *\left(\frac{y-8.745}{13.548}\right)$

$$
\begin{gathered}
C_{4} *\left(1-\frac{y-13.548}{26.5}\right)+C_{5} *\left(\frac{y-13.548}{26.5}\right) \\
C_{5} *\left(1-\frac{y-26.5}{31.352}\right)+C_{6} *\left(\frac{y-26.5}{31.352}\right)
\end{gathered}
$$

Now we write the expression of the overall pitching moment with respect to the neutral point of the aircraft. As the neutral point stays constant with changes to angle of attack, we will do our analysis at 0 degrees angle of attack to simplify the calculations. We have that:

$$
\begin{gathered}
M_{a c}=\int_{-31.352}^{31.352}\left(h-D_{Q}(y)\right) * L(y) d y+\int_{-31.352}^{31.352} C_{\frac{m c}{4}}(y) * C(y)^{2} * \frac{1}{2} \rho v^{2} d y \\
-(h-C . G .) * m g
\end{gathered}
$$

where $h$ is the position of the neutral point with respect to the front of the aircraft, C.G. is the position of the center of gravity with respect to the front of the aircraft, and $C_{\frac{m c}{4}}(y)$ is the moment coefficient of each airfoil section measured at the quarter chord, as a function of span. The first integral is the moment contribution due to lift, the second is the moment contribution due to the airfoil sections' moments, and the last is due to the moment contribution due to weight.

Note that by the definition of the neutral point, $\frac{d M_{a c}}{d \alpha}=0$. Therefore, if we differentiate both sides with respect to angle of attack, we have that

$$
\frac{d M_{a c}}{d \alpha}=0=\frac{d}{d \alpha} \int_{-31.352}^{31.352}\left(h-D_{Q}(y)\right) * L(y) d y
$$

Now we expand the integral into its piecewise components: 


$$
\int_{-31.352}^{31.352}\left(h-D_{Q}(y)\right) * L(y) d y=2 * \int_{0}^{31.352}\left(h-D_{Q}(y)\right) * L(y)
$$

And

$$
\begin{aligned}
& \int_{0}^{31.352}\left(h-D_{Q}(y)\right) * L(y) \\
&=\int_{0}^{6.559}\left(h-D_{Q}(y)\right) * L(y) d y+\int_{6.559}^{8.745}\left(h-D_{Q}(y)\right) * L(y) d y \\
&+\int_{8.745}^{13.548}\left(h-D_{Q}(y)\right) * L(y) d y+\int_{13.548}^{26.5}\left(h-D_{Q}(y)\right) \\
& * L(y) d y+\int_{26.5}^{31.352}\left(h-D_{Q}(y)\right) * L(y) d y
\end{aligned}
$$

We then consider the derivative of each integral separately. We will only show the analysis of the first integral here; the remainder of the cases are identical.

$$
\begin{gathered}
\frac{d}{d \alpha}\left(\int_{0}^{6.559}\left(h-D_{Q}(y)\right) * L(y) d y\right)= \\
\frac{1}{2} \rho v^{2} * \frac{d}{d \alpha}\left(\int_{0}^{6.559}\left(h-D_{Q}(y)\right) * C(y) * C_{L}(y) d y\right)
\end{gathered}
$$

We ignore the effects of angle of incidence on chord, as the largest angle of incidence used is only 1.4 degrees. Using the piecewise parts of $D_{Q}(y), C(y)$, and $C_{L}(y)$ applicable here, we have that the above is equivalent to

$$
\begin{aligned}
& \frac{1}{2} \rho v^{2} * \frac{d}{d \alpha}\left(\int_{0}^{6.559}(h-(1.054 y+7.9245)) *(-1.5402 y+31.698)\right. \\
& *\left(\left(k_{1}\left(\alpha_{1}+\alpha\right)+b_{1}\right) *\left(1-\frac{y}{6.559}\right)+\left(k_{2}\left(\alpha_{2}+\alpha\right)+b_{2}\right)\right. \\
&\left.\left.*\left(\frac{y}{6.559}\right)\right) d y\right)
\end{aligned}
$$


This can then be evaluated symbolically using MATLAB, and is equivalent to:

$$
\frac{1}{2} \rho v^{2}\left(92.9102 * h * k_{1}-1013.3 * k_{2}-937.6449 * k_{1}+81.8669 * h * k_{2}\right)
$$

After this process is done on the remainder of the cases, all the integrals are added and set equal to 0 . The constant terms ( $\operatorname{such}$ as $\frac{1}{2} \rho v^{2}$ ) are divided out, and we are left with a formula in terms of only the lift curve slopes and $h$. We substitute the values from Table 5: Airfoils and Angles of Incidence, to find that $h$ is approximately 16.08 , or that the neutral point of the aircraft is 16.08 meters from the front of the aircraft. 